NIPER-663

Distribution Category UC-122

\title{
IMAGING TECHNIQUES APPLIED TO THE STUDY OF FLUIDS IN POROUS MEDIA
}

By

L. Tomutsa

A. Brinkmeyer

D. Doughty

April 1993

Work Performed Under Cooperative Agreement No. DE-FC22-83FE60149

Prepared for

U.S. Department of Energy

Assistant Secretary for Fossil Energy

Robert Lemmon, Project Manager

Bartlesville Project Office

P. O. Box 1398

Bartlesville, OK 74005

Prepared by

IIT Research Institute

National Institute for Petroleum and Energy Research

P.O. Box 2128

Bartlesville, OK 74005 
TABLE OF CONTENTS

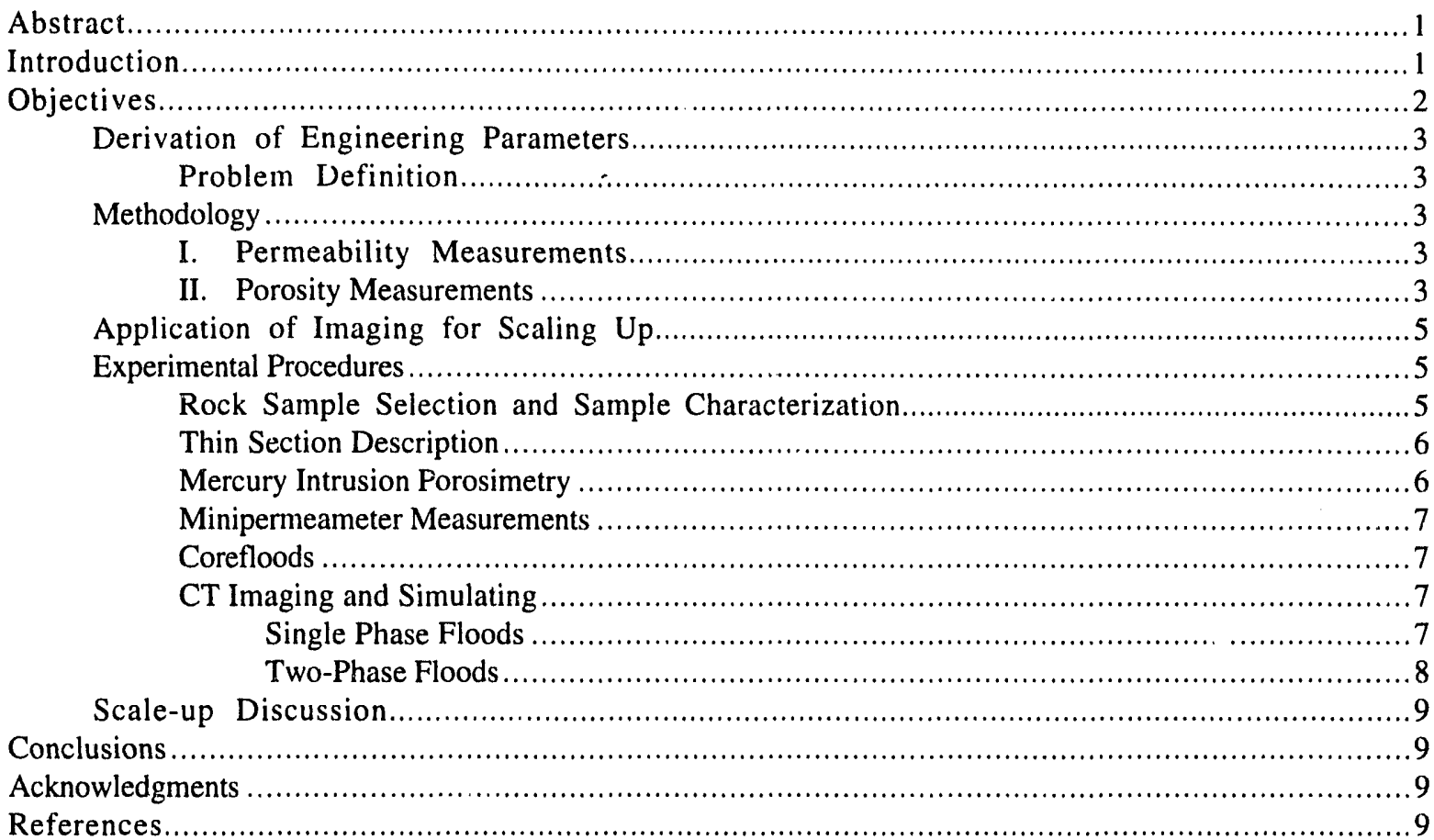

\section{ILLUSTRATIONS}

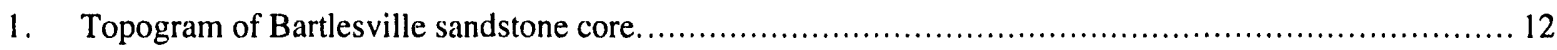

2. Photograph of slabbed sandstone core showing healed fracture .................................................. 13

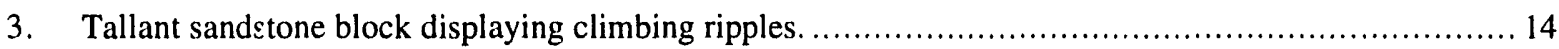

4. Tallant sandstone Photomicrographs; A - Magnification: 15X. A low magnification view of a very fine-grained, very well-sorted, matrix-laminated, subarkosic sandstone with subparallel, arcuate matrix laminae. B - Magnification: 100X. A detailed view of the laminar concentration of detrital clay matrix and abundant intergranular macro porosity within the sandstone flanking the matrix laminae. The pore network displays excellent interconnectivity, especially parallel to laminae. Scattered heavy minerals accompany the band of clay-rich sandstone.

5. Tallant sandstone SEM photomicrographs. A - Abundant intergranular macroporosity is distributed throught the figure; B - A partially disolved feldspar grain is displayed in the center of the figure; $\mathrm{C}$ and $\mathrm{D}$ - illustrate a portion of the sandstone characterized by laminar concentrations of detrital and authigenic clay matrix. C - Clay matrix drapes detrital grain surfaces (center). D - Pore-filling clay consisting of a combination of kaolinite and illite is displayed.

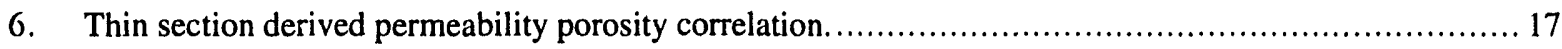

7. Thin section image analysis derived permeability profile..................................................... 17

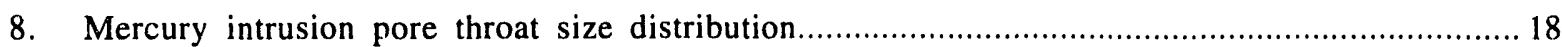

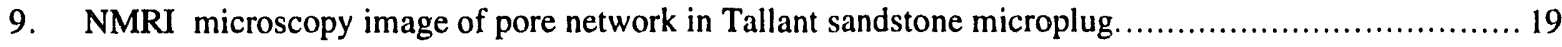




\section{ILLUSTRATIONS-Continued}

\section{Page}

10. Minipermeameter profile across sample end. 19

11. Minipermeameter values along sample side. 20

12. Porosity distribution in a vertical/longitudinal plane: (a) from $\mathrm{CT}$; (b) from Turning Bands 21

13. Permeability distribution in a vertical/longitudinal plane. 22

14. Tracer test observed by CT. 23

15. Tracer test simulation using $\mathrm{CT} /$ thin section image analysis data. 24

16. Tracer test simulation using Turning Bands generated data...................................................... 25

17. Oil flood $(1 \mathrm{cP})$ of $100 \%$ brine saturated Tallant sandstone sample. CT measurements. .26

18. Oil flood ( $1 \mathrm{cP})$ of $100 \%$ brine saturated Tallant sandstone sample. - Simulation using $\mathrm{CT} /$ thin section image analysis data.

19. Oil flood ( $1 \mathrm{cP})$ of $100 \%$ brine saturated Tallant sandstone sample. - Simulation using Turning Bands generated data.

20. Brine production curves, $1 \mathrm{cP}$ oil 29

21. Oil saturation distributions at residual brine (CT measurements). 30

22. Average oil saturation longitudinal profile at residual brine (CT measurements). 31

23. Vertical profile of oil saturation at residual brine (CT measurements). .31

24. Correlation of oil saturation at residual brine vs. porosity. 32

25. Waterflood $(1 \mathrm{cP})$ of oil saturated (residual brine) Tallant sandstone sample. - CT measurements. 33

26. Waterflood ( $2.6 \mathrm{cP})$ of oil saturated (residual brine) Tallant sandstone sample - CT measurements......... 34

27. Waterflood $(23 \mathrm{cP})$ of oil saturated (residual brine) Tallant sandstone sample - CT measurements........... 35

28. Waterflood ( $1 \mathrm{cP}$ ) of oil saturated (residual brine) Tallant sandstone sample - Simulation using $\mathrm{CT} /$ thin section image analysis data.

29. Waterflood (1 cP) of oil saturated (residual brine) Tallant sandstone sample. - Simulation using Turning Bands generated data

30. Waterflood $(1 \mathrm{cP})$ of oil saturated (residual brine) uniform permeability sample (simulation) 38

31. Oil production curves, $1 \mathrm{cP}$ visocisty....... 39

32. Oil saturation distributions at residual oil (CT measurements). 40

33. Average oil saturation longitudinal profile at residual oil (CT measurements). 41 


\title{
IMAGING TECHNIQUES APPLIED TO THE STUDY OF FLUIDS IN POROUS MEDIA
}

\author{
Scaling up in Class I reservoir type rock
}

By L. Tomutsa, A. Brinkmeyer and D. Doughty

\begin{abstract}
A synergistic rock characterization methodology has been developed. It derives reservoir engineering parameters from X-ray computed tomography (CT) scanning, computer assisted petrographic image analysis, miniperrneameter measurements, and nuclear magnetic resonance imaging (NMRI). Computed tomography is used to determine core spatial distribution of porosity and fluid saturations during corefloods. Computer-assisted petrographic image analysis of core sample thin sections generates pore size and shape data. It enables the calculation of two-dimensional porosity and permeability distribution averages over regions with sizes comparable with the scale of CT voxels and porosity/permeability correlations. The permeability distributions can be verified by using minipermeameter measurements performed on the surface of the sample. Using these porosity-pcrmeability correlations and the three-dimensional porosity distributions from CT scanning, threedimensional permeability distributions are generated for the entire core sample. NMR microscopy, which can yield resolutions down to 20 microns, is next used to provide threedimensional pore network images in small samples ( $5 \mathrm{~mm}$ diameter). The small samples are selected to represent the various rock types identified by CT, thin section, and minipermeameter. This approach provides the pore level information needed to understand the fluid behavior observed in CT images at larger scale.
\end{abstract}

This rock characterization methodology is used to investigate the effect of small-scale rock heterogeneity on oil distribution and recovery. It is also used to investigate the applicability of imaging technologies to the development of scaleup procedures from core plug to whole core, by comparing the results of detailed simulations with the images of the fluid distributions observed by
CT scanning. By using the rock and fluid detailed data generated by imaging technology described, one can verify directly, in the laboratory, various scaling up techniques. As an example, realizations of rock properties statistically and spatially compatible with the observed values are generated by one of the various stochastic methods available (turning bands) and are used as simulator input. The simulation results were compared with both the simulation results using the true rock properties and the fluid distributions observed by CT. Conclusions regarding the effect of the various permeability models on waterflood oil recovery were formulated.

\section{Introduction}

This project supports reservoir description and advanced oil recovery process research and development, especially in the areas of reservoir chemistry, physics, and rock-fluid interactions at the micro- and macroscopic scales. This work is aimed at advancing the understanding of the effect of small-scale rock heterogeneities (pore to whole core scales) on fundamental processes involved in oil recovery by developing, applying and refining cross-cutting imaging techniques and technologies. While these imaging techniques are currently used to provide near-term field RD\&D support in the characterization of pore structures and surfaces, and rock/fluid interactions as applied to the evaluation of enhanced oil recovery processes for Class I, II, and other reservoirs, in this report the emphasis is on the longer-term application of these techniques to the study of oil trapping, recovery mechanisms, and scaling-up procedures from core plug to whole core to interwell scales.

Numerical reservoir simulation studies provide critical information for overall $r$ servoir management, initiation of secondary recovery projects, and selection of optimum enhanced oil recovery (EOR) processes. Without a realistic geologic and engineering reservoir description, 
simulation results may be substantially in error. Depending on the degree and scale of reservoir heterogeneity, the level of detail obtainable from subsurface sampling is often inadequate to assign simulation parameters accurately to predict fluid flow on the interwell scale. Quantitative descriptions for simulation at scales less than well spacing can be obtained, however, by combining available subsurface reservoir data with a detailed quantitative model of rock composition and fluid flow characteristics constructed through statistical sampling and analysis of analogous outcrops. ${ }^{1}$

As early as the 1950 s Muskat ${ }^{2}$ derived analytical formulas for flow in a stratified reservoir, while Dykstra and Parsons ${ }^{3}$ defined their well known coefficient which characterizes the reservoir heterogeneity and estimates the waterflood sweep efficiency in a layered heterogeneous reservoir. ${ }^{4}$ The advent of computers allowed the introduction of detailed studies of the effect of random spatial distributions of permeability values on singlephase fluid flow using Monte Carlo numerical simulators. 5 Due to the statistical nature and spatial correlation of many rock heterogeneities, the geostatistical approach is often used to generate maps of simulator input parameters (permeability, porosity, saturations, etc.) and the uncertainties in these values. However, these maps are typically smoother than the actual distribution in the reservoir. ${ }^{6}$ By creating reservoir models statistically compatible with existing data and by running numerical flow simulations on these models, a range of outputs is obtained, and an uncertainty in the simulation results based on the uncertainty in the input data can be computed. In a systematic approach for handling heterogeneities from small to large scale by using pseudo functions it was found that while small-scale heterogeneities mainly cause oil trapping, the medium- and large-scale heterogeneities control lateral and vertical communication and ultimate oil recovery. ${ }^{7}$ Another successful approach to generate permeability distributions used fractals. ${ }^{8}$ The method described is based on the scale range $(\mathrm{R} / \mathrm{S})$ analysis of porosity in a 1,100 -ft-thick reservoir and lateral extrapolation of the reservoir properties by generating synthetic logs based on the observed fractal behavior. A revieu of the application of various stochastic modeling techniques used to create reservoir representations is given by Haldorsen and Damsleth. ${ }^{\text {The }}$ stochastic modeling technique selected should match the basic structure of the reservoir such as layer cake, jig-saw or labyrinth type, 10 and the statistical and spatial information regarding the reservoir rock types present should be available from cores, logs, or analogous outcrops.

In studies of the effect of small-scale heterogeneities on core relative permeabilities, it was found that channel-like effects can significantly alter the measurement results. ${ }^{11}$ Simulations of flow in crossbedded reservoirs by using pseudo relative permeabilities showed that oil trapping takes place behind the higher permeability foreset laminae. ${ }^{2}$ The advent of nondestructive imaging technologies such as CT and NMRI allows direct visualization and measurement of rock properties and of fluid distributions in rock samples. ${ }^{13-17}$ Thus, they provide the necessary tool to verify directly, in the laboratory, the various scaling up techniques which up until now could be verified only indirectly in the field. In the present work, values for the rock parameters (porosity, permeability), generated by CT, minipermeameter, and computer aided petrographic image analysis are used either directly as input data for simulating floods which are monitored by $\mathrm{CT}$, or they are used to generate realizations of rock properties $(k, \emptyset)$ statistically and spatially compatible with the observed values by means of the turning bands method ${ }^{18-19}$ and these realizations are used as simulator input. The effect of permeability models with varying amounts of detail, as well as viscosity ratio and grid block size, on waterflood oil recovery was determined. The numerical simulator used in this study is BOAST-VHS, ${ }^{20-21}$ NIPER's improved version of BOAST.

\section{Objectives}

The two objectives addressed in this study were:

1. To develop a methodology to derive reservoir engineering parameters from petrographic, computed tomography (CT) scanning, and nuclear magnetic resonance (NMR) imaging.

2. To investigate the applicability of imaging technologies to the development of scaleup procedures from core plug to whole core to interwell scale. 


\section{Derivation of Engineering Parameters}

\section{Problem Definition}

Determine the small (millimeter) scale porosity, permeability, and saturation variations in heterogeneous cores in which laboratory floods are performed.

\section{Methodology}

\section{Permeability Measurements}

1. The surface permeabilities of the core are measured using a fine tip minipermeameter $(3 \mathrm{~mm}$ ID O-ring).22-23 By calibrating the minipermeameter with homogeneous core plugs of known permeabilities, the accuracy of the measurements is within $10 \%$. The minipermeameter measurements are used to determine the variations in rock permeability due to small-scale heterogeneities. The minipermeameter is limited to surface permeability measurements. To determine the permeabilities within the rock sample, thin section image analysis is used.

2. After the minipermeameter measurements are performed, thin sections are made from the core at the locations where minipermeameter measurements were taken.

3. The thin sections are then analyzed using PIA. A dedicated computer is used to capture and digitize thin section images generated from a petrographic microscope using either transmitted of fluorescent light. A segmentation process is then applied which differentiates the pore space from the rock matrix and the computer performs automatic measurements on the pores. ${ }^{24-25}$ These measurements are used to calculate average porosity and permeability values for the thin section image. Forty images are captured from each thin section, the associated porosity and permeability values are computed for each image, and a permeability/porosity correlation is calculated. The porosity and permeability values are calculated at scales equal to the scale of the image captured $(0.5 \mathrm{~mm} \times 0.5 \mathrm{~mm})$. The image analysis porosity values are verified against the $C T$ values and the image analysis averaged permeability values are compared with the minipermeameter measured values. Small adjustments in the porosity and permeability values generated by image analysis can be made by adjusting the segmentation threshold and the tortuosity.

\section{Porosity Measurements}

4. X-ray computerized tomography (CT) is used to determine the three-dimensional porosity distribution within the core at scales equal to the voxel size $(0.5 \times 0.5 \times 2 \mathrm{~mm})$. CT technology has been adapted to measure spatial variations in rock porosity and oil and brine saturations in reservoir rock samples during flow experiments. The operating parameters of the CT scanner allow imaging of samples with lengths of up to 1.5 meters and diameters of up to 15 centimeters. The rapid scan time $(20 \mathrm{sec} / \mathrm{scan})$ of the CT scanner permits taking the large number of scans, necessary to adequately describe the rock and fluid spatial distributions. These scans are rapidly transferred from the CT scanner to the image processing workstation for computation and dispiay of porosity and saturation distributions, according to the following formulas: 26

Porosity:

$$
\varnothing=\left(Y_{\mathrm{bm}}-Y_{\mathrm{gm}}\right) /\left(Y_{\mathrm{brinc}}-\mathrm{Y}_{\mathrm{gas}}\right)
$$

where:

$$
\begin{aligned}
& \emptyset=\text { Porosity } \\
& Y_{b m}=\begin{array}{l}
\mathrm{CT} \text { attenuation of } 100 \% \text { brine } \\
\text { saturated core, H.U. }
\end{array} \\
& \mathrm{Y}_{\mathrm{gm}}=\mathrm{CT} \text { attenuation dry core, H.U. } \\
& \mathrm{Y}_{\text {brine }}=\begin{array}{l}
\mathrm{CT} \text { attenuation of } \\
\text { brine, H.U. (constant) }
\end{array} \\
& \mathrm{Y}_{\text {gas }}=\begin{array}{l}
\text { CT attenuation of air, H.U. } \\
\text { (constant) }
\end{array}
\end{aligned}
$$

\section{Saturation:}

$$
\begin{aligned}
& \mathrm{S}_{\mathrm{o}}=\left(\mathrm{Y}_{\text {bgom }}-\mathrm{Y}_{\mathrm{bm}}\right) /\left(\varnothing\left(\mathrm{Y}_{\text {brine }}-\mathrm{Y}_{\mathrm{oil}}\right)\right) \\
& \mathrm{S}_{\mathrm{w}}=1-\mathrm{S}_{\mathrm{o}}
\end{aligned}
$$

where: 


$$
\begin{aligned}
& \mathrm{S}_{\mathrm{O}} \quad=\text { Oil saturation } \\
& \mathrm{S}_{\mathrm{w}} \quad=\quad \text { Brine saturation } \\
& Y_{\text {bgom }}=\text { CT attenuation of core, con- } \\
& \text { taining both brine and oil H.U. } \\
& \mathrm{Y}_{\mathrm{bm}}=\mathrm{CT} \text { attenuation of } 100 \% \text { brine } \\
& \text { saturated core, H.U. } \\
& \emptyset \quad=\text { Porosity, fraction } \\
& \mathrm{Y}_{\text {brine }}=\mathrm{CT} \text { attenuation of brine, } \\
& \text { (constant) H.U. } \\
& \mathrm{Y}_{\mathrm{oil}}=\mathrm{CT} \text { attenuation of oil, } \\
& \text { (constant) H.U. }
\end{aligned}
$$

To be able to perform subtraction of the voxels located at identical positions in the core but with different states of saturation, a positioning table with an accuracy of 13 microns, is used.26 The accurate positioning table allows not only accurate computations of porosity and saturation for one coreflood but, combined with a repositioning procedure of the core on the table allows multiple experiments, to be run simultaneously on the CT scanner.

5. The porosity values determined by CT and the permeability/porosity correlation from the thin section image analysis are used to construct the three-dimensional permeability distribution within the core sample.

6. By comparing the simulations using the porosity and permeability values determined above to the distributions observed by CT, the accuracy of the above approach for a specific sample can be evaluated.

7. MMR microscopy is used to provide threedimensional pore network images to understand how pore-scale rock geometry and fluid distributions relate to larger scale permeabilities and fluid saturations. Nuclear magnetic resonance imaging (NMRI) is another nondestructive imaging technology used to image fluids within cores. A commercial high-resolution Fourier Transform NMR spectrometer has been modified to be used as a high resolution imaging instrument. A maximum image resolution of 20 microns has been achieved. 27 By comparison, NMRI instruments adopted from the medical field generally have about 500 -micron resolution. The high resolution allows visualization of the effect of rock/fluid interaction on oil, water, and gas distributions within pore spaces of reservoir rocks. Previous resolution limitations have been overcome by interfacing two desk top computers with the NMR spectrometer. One desk top computer controls the imaging process by stepping the current pulses in high magnetic field gradient coils and the image data acquisition sequence with also a recently built sample probe. The other one, which has a high-speed RISC processor, performs all the computations necessary to generate the fluid image.

For small-scale studies by NMRI, small core plugs (4-5 $\mathrm{mm}$ diameter, 6-8 $\mathrm{mm}$ long) are needed. A micro coring apparatus has been built to cut such core plugs from the large plug in regions identified by $\mathrm{CT}$ as being of interest. Next, the small core plugs are placed in Teflon micro core holders and placed in the NMRI probe for data acquisition for the high resolution NMRI images of the fluids at the pore level. Due to the difficulty of preserving the saturation in the microplugs during cutting, the microplugs were cleaned and resaturated after cutting, and images of fluids in the rock pores were acquired for either single-phase or two-phase end point saturations (residual oil and residual brine).

Two basic methods have been used in this work for reconstructing the 3-D image from the raw projection data in projection reconstruction NMRI: (1) A direct approach based on the application of the Radon transform in three dimensions and (2) a two-stage reconstruction involving two successive applications of standard 2-D Radon transforms. This method is more efficient, involving approximately $2 \mathrm{~N}^{4}$ operations to reconstruct the entire 3-D image where $\mathrm{N}$ is the cubical dimension of the image. The major shortcoming in this approach is the impossibility of reconstructing only part of the image; the complete image must be reconstructed. This increases the overall computer requirements both for time and large file handling and storage capability. With the direct approach, reconstruction of the complete 3-D image involves approximately $\mathrm{N}^{5}$ operations which would require much more time if the reconstruction of the entire image would be required. However, the direct approach does permit a partial reconstruction of selected regions of the image, for example a single slice view of arbitrary orientation, or a reduced volume image using only a subset of the raw data, which is the most common occurrence. Because the acquisition of the data is the limiting factor, imaging the central volume of a sample at high 
resolution would be possible with a reduced number of raw projections using the direct approach. A FORTRAN program implementing the direct reconstruction algorithm has been obtained and modified to be compatible with our data acquisition format. It has been tested on a 3$D$ image data set obtained from a sandpack and produces good images of arbitrary slices of the sample. This method also does not seem to be as susceptible to image artifacts which appear in reconstructed images. The direct image reconstruction approach, allows in sandstones with low iron content, spatial resolutions down to 25 microns. Also, the use of animation in successive displays of cross sections through the volume studied seems to have the potential of helping to extract topological characteristics of the pore network from NMRI images. The integration of these techniques enables a more definitive assessment of the roles of heterogeneities in affecting oil entrapment, fluid flow and fluid saturation distribution.

The application of this methodology for permeability calculation is illustrated for the sample used in the sualing experiments described below.

\section{Application of Imaging for Scaling Up}

Scaling procedures have been studied both experimentally and through simulations by using reservoir samples representative of Class I reservoirs. Minipermeametry and CT scanning was used to measure porosity, permeability and fluid distributions in samples with sizes ranging from $2.5-12 \mathrm{~cm}$. across and $5-30 \mathrm{~cm}$. long to characterize the various heterogeneity scales. Pore geometries and fluid distribution in locations where oil trapping takes place were studied by means of computer image analysis of thin sections and high resolution NMRI. Using these data, insights into scaling procedures can be derived for the laboratory corefloods measured. The scaling procedures and the heterogeneities found at the above scales will be used as intermediate steps in deriving scale-up procedures for interwell regions.

\section{Experimental Procedures Rock Sample Selection and Sample Characterization}

To carry out the scaling up work, information at various scales needs to be used. The use of outcrops provides information at scales from hundreds of meters to centimeters. Suitable outcrops located within a close distance to NIPER have been identified during field trips to various fluvial deltaic outcrops (Bartlesville sandstone formation) in Northeastern Oklahoma. The field trips allowed direct viewing of characteristic heterogeneities and selection of samples for core floods. Rock samples containing generic heterogeneities characteristic of fluvial deltaic deposition environments (small scale crossbedding and ripple bedding) were collected and cut in rectangular shape for observation of small scale heterogeneities and for minipermeameter measurements.

To accelerate the evaluation of cores, the topogram capability of the CT scanner has been combined with the high accuracy positioning system to generate longitudinal cross sections of the cores in one pass. The topogram, which generates a projection of the core in only one plane, similar to the traditional medical X-ray radiography, can provide rapid identification of sedimentary, diagenetic and structural features in unslabbed, unprocessed cores. A longitudinal cross section of a $25 \mathrm{~cm}$. long section of core can be generated in approximately 20 -sec. This yields a reduction in time and file sizes by a factor of at least 30 compared to the previous approach in which a longitudinal cross section was generated from transverse crossections. Selection of three different projection planes parallel to the core axis $\left(0^{\circ}, 45^{\circ}\right.$ and $\left.90^{\circ}\right)$, facilitates the rapid determination of the preferential slabbing plane and the optimum locations and directions for cutting plug samples. Figure 1 shows the topogram in three planes for an unslabbed $7.5 \mathrm{~cm}$. diameter core, from the Bartlesville Sandstone formation in northeastern Oklahoma. Figure 2 shows the same core slabbed in a plane parallel to projection $1\left(0^{\circ}\right)$. Apparent in projection $1-\left(0^{\circ}\right)$ of Fig. 1 and in Fig. 2 is a calcite filled fracture (vertical light color line between depth $70.25 \mathrm{ft}$ and $71 \mathrm{ft}$ ). Calcite cemented zones are visible as wide, white areas in the higher part of the core in all three projections of Fig. 1 and in Fig. 2, while crossbedding is visible between $70.5 \mathrm{ft}$ and $71 \mathrm{ft}$ in Fig. 1, projection $1-\left(0^{\circ}\right)$. 
For this study, a sample with climbing ripples was selected. This sample was cut parallel to the laminations from a block collected from an outcrop exposure of the Tallant Formation in northeastern Oklahoma (Fig. 3). Its dimensions are $25.5 \times 5.6 \times 5.1 \mathrm{~cm}$. Its volumetric porosity is $26.0 \%$ and the brine permeability measured parallel to the laminations is $210 \mathrm{mD}$.

The Tallant formation of Virgil age (upper Pennsylvanian) is overlying the Barnsdall formation and underlying the Vamoosa formation. The yellowish color sample is very fine-grained (100 microns) to fine-grained (125 microns) ripple-formed and wavy-bedded sandstone. Matrix lenses commonly drape the foreset laminae within the ripple bed sets. Ripples are asymmetric 2 to $5 \mathrm{~cm}$ long and 0.3 to $1.0 \mathrm{~cm}$ high. Coaly material and tiny wood fragments tend to concentrate in ripple troughs. This sandstone is probably of fluvial origin. No obvious calcite cementation has been found in the rock matrix, but it was present on the fracture planes.

\section{Thin Section Description}

Two representative thin section photomicrographs (Figs. $4 \mathrm{~A}$ and $\mathrm{B}$ ) and four SEM views (Figs. 5A-D) display characteristic features of this sandstone.

The thin sections show a very fine-grained, very well-sorted, rounded, matrix-laminated, subarkosic sandstone. The mean grain diameter is approximately $0.11 \mathrm{~mm}$, with a maximum grain diameter of $0.29 \mathrm{~mm}$. The sedimentary fabric is mildly compacted, and displays common point-topoint intergranular contacts, as well as locally deformed ductile grains (mica and sedimentary rock fragments) and matrix laminae. The laminae are characterized by increased concentrations of dolomite cement and hematite cement. They are less porous and more lithic rich and more densely compacted than the adjoining sandstone. Deformation of the matrix-rich sedimentary rock fragments has locally yielded patches of pseudo matrix. The sandstone is ripple laminated, and matrix lenses commonly drape the foreset laminae within the ripple bed sets. The detrital composition is dominated by monocrystalline quartz, together with subordinate amounts of plagioclase feldspar, polycrystalline quartz, and sedimentary rock fragments (shale and mudstone). Minor detrital components include chert, metamorphic rock fragments, volcanic rock fragments, mica, epidote, amphibole, and undifferentiated opaque minerals. The authigenic mineralogy is dominated by quartz overgrowth cement. The quartz overgrowths typically occur as thin rims of synthaxial cement flanking the detrital quartz grains. In addition to quartz cement, scattered clusters of iron oxide and pyrite cement are present throughout the framework as replacements or leached, iron-rich and/or organic matrix is present in the form of thin, organic-rich, illitic matrix laminae. Authigenic clay matrix minerals include kaolinite and minor amounts of illite, which are present as replacements for leached feldspar grains, and less commonly, metastable rock fragments. The macro pore volume is comprised of very well-preserved primary porosity, together with common to abundant secondary (intragranular and grainmoldic) porosity. The secondary voids have developed chiefly due to the partial to complete dissolution of feldspar grains. Macro porosity is visually estimated to account for approximately $27 \%$ of the bulk volume within this sandstone. The framework displays an excellent interconnectivity of pore space, which should result in good horizontal permeability values. The presence of the detrital matrix laminae is likely to result in significantly lower vertical permeabilities for this sandstone. X-ray diffraction mineral percentages are: quartz-94\%, feldspar-4\%, kaolinite- $1 \%$, illite- $1 \%$.

Images were captured from the thin section using a $5 x$ objective. The thin section generated porosity-permeability correlation is displayed in Fig. 6 and a permeability profile from the thin section data across one of the sample ends is shown in Fig. 7.

\section{Mercury Intrusion Porosimetry}

Mercury intrusion porosimetry (Fig. 8) shows $60 \%$ of the pore throats having diameters larger than 5 microns and $20 \%$ of the pore throats having diameters smaller than 1 micron. While most of the sample contains clean high permeability sandstone (larger pore throats), a significant fraction of the sample, has low porosity, permeability region which are localized in the clay rich, cemented laminae (smaller pore throats). NMRI microscopy (Fig. 9) also shows that in the regions with clay rich laminations the pores are smaller than in the cleaner zones. The region where no pores are shown in Figure 9 is within a clay rich laminations where the pores are smaller than 50 microns, which is the resolution 
limit for this sample. In the cleaner zone, pores with diameters as large as 250 inicrons are seen.

\section{Minipermeameter Measurements}

In Fig. 10 is shown one of the three profiles measured by minipermeameter at the end of the sample. The profiles were taken in a direction perpendicular to the clay rich laminations. They show less permeability contrast than the thin section data. This is due to the minipermeameter tip diameter size $(3 \mathrm{~mm})$, which by being larger than the laminations (1-2 mm thick), causes an averaging effect of lamination and clean sand to take place. Permeabilities measured on the side where the laminations intersect the surface at a small angle such that the entire minipermeameter tip is covered by the laminations, have lower values, in better agreement with the image analysis values (Fig. 11).

\section{Corefloods}

\section{CT Imaging and Simulating}

\section{Single Phase Floods}

To identify dynamically the permeability contrasts due to rock heterogeneities tracer tests were performed on the Tallant block. The block was first encapsulated in Castolite ${ }^{\mathrm{TM}}$, saturated with untagged $2 \% \mathrm{KCl}$ brine and the porosity of the sample determined by CT scanning. To reconsiruct a longitudinal crossection (Fig. 12A), sets of 63 , two-dimensional transversal CT images $256 \times 256$ pixels each are captured for the sample under vacuum, fully saturated with brine and during the various floods. Due to computational limitations, this study was performed only on longitudinal two dimensional sections of the sample. The average value of porosity determined by CT was $25.3 \%$ corresponding to the brine X-ray attenuation of 1554 H.U. The porosity values at the scale of the CT voxel vary between $19 \%$ for the clay rich ripples to $29 \%$ for the most clean sand areas.

The corresponding permeability distribution generated using the correlation from thin sections image analysis is shown in Fig 13A. The average permeability was calculated to be $210 \mathrm{mD}$ using the CT porosity and the permeability/porosity correlation from thin section image analysis. The permeability values at the scale of the CT voxel vary between $90 \mathrm{mD}$ for the clay rich ripples to $400 \mathrm{mD}$ for the most clean sand areas.
For comparison, in Figs, 12B,C,D are shown the porosity distributions generated using the Turning Bands method in which correlation lengths of $3.2 \mathrm{~cm}$ horizontally and $0.3 \mathrm{~cm}$ vertically were used. Figure 13 compares permeabilities from $\mathrm{CT}$ and one Turning Bands realization. The figures show that the Turning Bands method describes adequately the spatial distribution of the rock heterogeneity.

A slug of $7 \%$ NaI tagged brine was injected and followed again by untagged brine. The tests were performed at two velocities, $30 \mathrm{~cm}$./day and $300 \mathrm{~cm}$./day. The observed and simulated tracer test fluid distributions are shown in Figs. 14 through 16. The CT image of the tracer test shows fine fingering due to the permeability contrast at millimeter scale. Also, a large central finger due to a central band of higher permeability is observed. In the simulations, continuous injection, instead of tracer slug was assumed and a grid of $63 \times 126$, which corresponds to grid block sizes of the CT voxel size, $(0.5 \mathrm{~mm} \times 0.5$ $\mathrm{mm} \times 4 \mathrm{~mm}$ long) was used. The simulations, while reproducing the general front movement observed by CT scanning, show less fingering. The factors contributing to the discrepancy between $\mathrm{CT}$ and simulation results are related to the limitations in both simulations and CT observations. On the simulation side, the main factors to consider are: (1) the relatively coarse grid compared to the heterogeneity scale; (2) the fact that this simulator does not take into account dispersion effects, and (3) performing a twodimensional simulation (in the $x z$ plane) of a system, which although displays layering in the $\mathrm{z}$ direction, does have a significant lack of translational symmetry in the y direction. To address these factors will require improvements in the simulator and the use of a faster computer to compensate for the expected increase in the simulation time. From the CT side, the main factor to consider is the spatial averaging of rock and fluid properties over the voxel volume which is an effect inherent in CT observations. This results in reducing the contrast between the high and low porosity/permeability values for sedimentary features which have sizes comparable to the voxel size. Thus, while the petrographic image analysis points to values of $50 \mathrm{mD}$ or less for the low permeability layers and over $500 \mathrm{mD}$ in the high peri eability layers in the climbing ripples, the low range for the CT derived permeabilities is near $100 \mathrm{mD}$ while the high range is near $300 \mathrm{mD}$. Higher $\mathrm{CT}$ resolutions (512 $\times 512$ instead of $256 \times 256$ voxels/image) 
would improve the quantitative characterization of heterogenities at the millimeter scale.

\section{Two-Phase Floods}

To study the effect of climbing ripples on initial and residual oil saturations and the fluid paths during oil removal, oil floods and waterfloods were performed using 1, 2.6 and 23 $\mathrm{cP}$ oil. Simulations were performed using the CT measured porosity and permeability values and the Turning Bands method generated values.

The first oil flood consisted of flooding the core previously saturated with $7 \% \mathrm{Nal}$ tagged brine with $90 \mathrm{pv}$ of $1 \mathrm{cP}$ Soltrol 100 mineral oil. The flow has been reversed 2 times to reduce the average saturation gradient between the inlet and outlet and the injection rate has been increased gradually from $28 \mathrm{~mL} / \mathrm{hr}$ to $480 \mathrm{~mL} / \mathrm{hr}$ while monitoring for fine migration. While at the lower injection rate only an average volumetric oil saturation of $44 \%$ could be reached, by increasing the injection rate, a final oil saturation of $66 \%$ has been reached without any evidence of fine migrations. The oil front movement during the ICP oilflood is shown in Fig. 17, and the corresponding simulations using the $\mathrm{CT} / \mathrm{image}$ analysis data in Fig. 18 and Turning Bands generated data in Fig. 19. The strong fingering present in figure 17 is controlled by the small scale heterogeneities (climbing ripples). An average saturation of $71.8 \%$ was observed by CT and $67 \%$ measured volumetrically. The simulation generated oil front displayed in Fig. 18 , while reproducing the three main fingers, due to the factors mentioned previously, is not able to reproduce the details of the front shown in Fig. 17. The front displayed in Fig. 19, reproduces statistically the oil flood behaviour shown in Fig. 17, which is expected, as the Turning Bands algorithm used did not involve conditioning simulations. The brine production curves associated with Figs. 17 and 18 are shown in Fig. 20. The difference between the two curves is due to the fact that the laboratory oil flood took place at gradually increased injection rates, until it reaches a rate of $56 \mathrm{ml} / \mathrm{hr}$. The simulation used the final end points observed for the two rock types present in the sample as measured by CT corresponding to the higher flow rate. The oil saturation distributions at the end of the oil flood for the three oil viscosities measured using CT are shown in Fig. 21. It is noticeable that an uniform average oil saturation has not been achieved in the direction of the flow. Using all the data present in the longitudinal crossection, a low correlation is found between the porosity and the oil saturation achieved at the irreducible brine stage. This is due to the saturation gradient between the inlet (position 0) and outlet (position 63 shown in Fig. 22). A good correlation is observed (Fig. 24) when only data from a vertical profile are taken, with all the points considered situated at the same distance from the inlet, (Fig. 23). Figure 24 shows clustered data. The data below $24 \%$ porosity correspond to the lower permeability ripples, for which the average residual oil saturation of 0.22 has been observed. The other data, corresponding to the clean sand, are centered at porosity 0.26 and oil saturation 0.75 . These values represent the end point oil saturations in the first drainage flood for the two rock types present in this sample.

Waterfloods were performed at a rate of 30 $\mathrm{cm} . /$ day using a $7 \% \mathrm{NaI}$ tagged brine for the cases with $1,2.6$ and $23 \mathrm{cP}$ oil. The CT observed floods for the three oil viscosities are shown in Figs. 25-27. Relatively sharp fronts are visible in all three figures. The residual oil saturation is in the range $0.35-0.40$ for the entire sample including both the high and low permeability rock (Fig. 32). The simulation results displayed are using: (1) the CT generated rock data (Fig. 28), (2) the Turning Bands data (Fig. 29) and (3) a homogeneous coarse grid $(13 \times 1 \times 26)$ equivalent case (Fig. 30). Figures 28 and 30 show fronts close to those observed by CT while Fig. 29 shows a more pronounced fingering. But, behind the front, eventually all the oil saturations reach the end point in the range $0.30-0.40$, depending on the distance from the inlet port, regardless of rock type. Figure 31 displays the cumulative oil production vs. water injected for both observed and simulated cases. One can see that the 100\% oil production is followed by a sudden breakthrough and near $100 \%$ water production. The homogeneous coarse grid simulation reproduces well the saturation distributions observed by CT. When all the data present in the longitudinal crossection are used, no correlation is observed between the porosity and the oil saturation achieved at the irreducible brine stage. This is due again to saturation gradients present between the inlet and outlet (Fig. 33). Even when only data from a vertical profile are taken, with all the points considered situated at the same distance from the inlet, only a weak correlation is generated. The final saturation distribution is controlled by a number of factors, some of which are: (1) The flow regime; (2) The amount fluid 
injected; (3) The size and permeability/capillary pressure contrast between the laminatins and the clean sand. Further investigation and refinement of the spatial resolution and the accuracy of the saturation determination by CT is needed.

\section{Scale-Up Discussion}

Selecting a heterogeneous rock sample with a complex structure, on which detailed measurements could be performed against which the simulation results could be compared, helps to remove many of the uncertainties in the simulation matching existent when crily production curves are used. The wate flcod experimental results could be reproduced not 'snly by a detailed simulation, including all ine rock data obtained from CT, minipermeameter and image analysis of thin sections but also by a much coarser simulation using uniform parameters. Two factors contributing to this occurence are: (1) the range of porosity, permeability and relative permeability contrasts between the two rock types within the sample; (2) the size, geometry and number of the heterogeneities compared to the size of the sample in which the experiment was performed. The large number of ripples uniformly distributed within the sanıple during waterflood dispersed the water front and actually prevented channeling creating the same effect as a homogeneous sample containing much smaller heterogeneities. The implication for laboratory work is that minimum representative sample size should be determined by the size, number and contrast in properiies of the smaller scale heterogeneities, if the theory used to interpret the data assumes uniform rock properties. Given that in this simulator the actual physical dimensions are not important, these results are also significant for field scale for similar heterogeneity distributions. Previous work' used only simulations and various permeability distributions derived from outcrop data to study the effect of heterogeneity on the oil recovery during waterflood. It showed that, at larger scales (meters to tens of meters), small scale heterogeneity compared to the volume studied could be accounted well by using homogeneous equivalent models. Heterogeneities with sizes comparable to the volume studied and which have high contrasts in permeability (up to 1 to 50 ratios) have to be accounted for either by using deterministic models (considered to be the most accurate) or by using stochastic models (by incorporating the accurate spatial correlation lengths). For these heterogeneities both the layered and uniform models gave predictions which were considerably different than the deterministic models.

\section{Conclusions}

A synergistic rock characterization methodology, which derives reservoir engineering parameters from X-ray computed tomography scanning, computer assisted petrographic image analysis, minipermeameter measurements, and nuclear magnetic resonance images has been developed.

This rock characterization methodology, together with fluid distribution measurements by CT can be effectively used to investigate the effect of small scale rock heterogeneity on oil distribution and waterflood recovery in a sample containing heterogeneities characteristic of Class I reservoirs.

Imaging technologies can be used in the development of scale-up procedures from core plug to whole core, by comparing the saturation distributions resulting from simulations with the saturation distributions resulting from CT scanning.

Even highly complex heterogeneous rock samples behave as uniform media if: (1) the contrasts between the petrophysical properties of the various rock types are relatively small; (2) the sample size is large compared to the sizes of the heterogeneities and (3) the number of the heteogeneities is large as to be amenable to statistical handling.

\section{Acknowledgments}

This work was supported by the U.S. Department of Energy under Cooperative Agreement DE-FC22-83FE60149. Bob Lemmon and Alex Crawley of the DOE Bartlesville Project Office are acknowledged for their help in conducting this work. The authors thank Michael Szpakiewicz for the sample geological description, Kevin Doggett and Ron Masias for help with the minipermeameter measurements, Pin $\mathrm{Hu}$ Wang for help with the computer simulations, Djuan Grissom for help with graphics, Edna Hatcher for stenographic work, and M. Madden, M. Tham, and T. E. Burchfield, all of NIPER, for their reviews of this work. 


\section{References}

1. Tomutsa, Liviu, Ming-Ming Chang and Susan Jackson, 1991. Application Of Outcrop Data For Characterizing Reservoirs And Deriving GridBlock Scale Values For Numerical Simulation, in Reservoir Characterization III Proceedings of Third International Reservoir Characterization Techical Conference, Tulsa, OK Nov. 3-5, 1991 ed Bartlesville, Pennwell Books, 1993, p. 151194.

2. Muskat, M., 1950. The Effect of Permeability Stratification in Complete Water Drive Systems. Trans., AIME, v. 189, pp. 349-358.

3. Dykstra, M. and R. L. Parsons, 1950. The Prediction of Oil Recovery by Waterflood. Secondary Recovery of Oil in the United States, 2nd Ed. API, pp. 160-170.

4. Willhite, G. P., 1986. Waterflooding. SPE monograph.

5. Warren, J. E. and H. S. Price 1961. Flow in Heterogeneous Porous Media. SPEJ, v. 1, no. 3, pp. 153-169.

6. Journel, A. G. and C. J. Huijbregts, 1978. Mining Geostatistics, Academic Press.

7. Lasseter, T. J., T. R. Waggoner and L. W. Lake, 1986. Reservoir Heterogeneities and Their Influence on Ultimate Recovery. In Reservoir Characterization. eds., L. W. Lake and H. B. Carroll, Academic Press, pp. 545-560.

8. Hewett, T. A., 1986. Fractal Distributions of Reservoir Heterogeneity and Their Influence on Fluid Transport. Pres. at 61st Ann. Technical Conf. and Exhib of SPE in New Orleans. SPE paper 15386.

9. Haldorsen, H. H., E. Damsleth, 1990. Stochastic Modeling, JPT, vol. 42, no. 4, pp. 405-412.

10. Weber, K. J. and L. C. van Geuns, 1989. Framework for Constructing Clastic Reservoir Simulation Models. Pres. at 69th SPE Annual Technical Conf and Exhibit, San Antonio, TX, SPE 19582.
11. Huppler, J. D., 1970. Numerical Investigation of the Effects of Core Heterogeneities on Waterflood Relative Permeabilities. SPEJ, v. 10, no. 4, pp. 381-392.

12. Kortekaas, T. F. M., 1985. Water/Oil Displacement Characteristics in Cross Bedded Reservoir Zones. Pres. at Soc. Petrol. Eng. 58th Ann. Tech. Conf. and Exhib., San Francisco; SPEJ, v. 15 , no. 6, pp. 917-926.

13. Withjack, E. M., 1988. Computed Tomography for Rock-Property Determination and Fluid-Flow Visualization, SPE Formation Evaluation, pp. 696-704.

14. Tomutsa, L., Mahmood, S. M., Brinkmeyer, A., and Honarpour, M., 1990. Application of Integrated Pore-to-Core Image Analysis To Study Fluid Distribution in Reservoir Rocks, Presentation at the 65th Annual Tech. Conf. and Exhib., New Orleans, LA. SPE 20478.

15. Tomutsa, L., Doughty, D., Brinkmeyer, A., and Mahmood, S., 1992. Imaging Techniques Applied to the Study of Fluids in Porous Media, Dept. of Energy Report No. NIPER-582.

16. Hicks Jr, P. J., H. A. Deans and K. Ram Narayanan, 1992. Distribution of Residual Oil in Heterogeneous Carbonate Cores Using X-Ray CT, SPE Formation Evaluation, p. 235-240.

17. Bahralolom, I. M. and Heller, J. P., 1992. Influence of Small-Scale Heterogeneities on Miscible Corefloods, Pres. at the SPE/DOE Eight Symposium on Enhanced Oil Recovery, Tulsa, OK. SPE/DOE 24113.

18. Wilson, J. L. and A. Gutjahr, 1989. Synthetic Generation of Random Permeability Fields for Heterogeneous Reservoir Simulation. Pres. at SPE Symposium on Reservoir Simulation, Houston, TX. SPE 18435.

19. Zimmerman, D. A. and J. L. Wilson, 1990. Description of and Users Manual for TUBA: A Computer Code for Generating Two-Dimensional Fields via the Turning Bands Method. Prepared by New Mexico Institute for Mining \& Technology. Distributed by GRAM, Inc, Albuquerque, New Mexico. 
20. Ming-Ming Chang, Tomutsa, L. and M.K.Tham, 1989. Predicting Horizontal/Slanted Well Production by Mathematical Modeling. Pres at SPE Production Operations Symposium, Oklahoma City, OK, March 13-14. SPE 18854.

21. Ming-Ming Chang, P. Sarathi, R. L. Heemstra, A. M. Cheng and J. F. Pautz, 1991. User's Guide and Documentation Manual for "BOAST-VHS for the PC" NIPER Topical Report NIPER-542, July.

22. Gogin, D. J., Thrasher, R. L., and Lake L. W. (1988b) Theoretical and Experimental Analysis of Minipermeameter Response Including Gas-Slippage and High-Velocity Flow Effects. In Situ, 12, 79-116.

23. Halvorsen, C. and Hurst, A., 1990. Principles, Practice and Applications of Laboratory Minipermeametry, Advances in Core Evaluation Accuracy and Precision in Reserves Estimation, Proceedings, the First Society of Core Analysts European Core Analysts Symposium, Edited by Worthington, P. F., London UK. p.521.
24. Ehrlich, R., Etris, E. L., Brumfield, D., Yuan, L. P., and Crabtree, S. J., 1991. Petrography and Reservoir Physics III: Physical Models for Permeability and Formation Factor", AAPG Bulletin, v. 75, No.10, pp. 1579-1592.

25. Tomutsa, L. and A. Brinkmeyer, 1990. Using Image Analysis to Determine Petrophysical Properties of Reservoir Rocks. DOE Report NIPER-440.

26. Tomutsa, L., D. Doughty, S. Mahmood, A. Brinkmeyer, M. P. Madden, 1991. Imaging Techniques Applied to the Study of Fluids in Porous Media. DOE Report NIPER-485.

27. Doughty, D.A. and L. Tomutsa, 1992. NMR Microscopy for Fluid Imaging at Pore Scale in Reservoir Rock, SCA-9222, The Society of Core Analysts Annual Meeting, Oklahoma City, OK, June 15-17. 

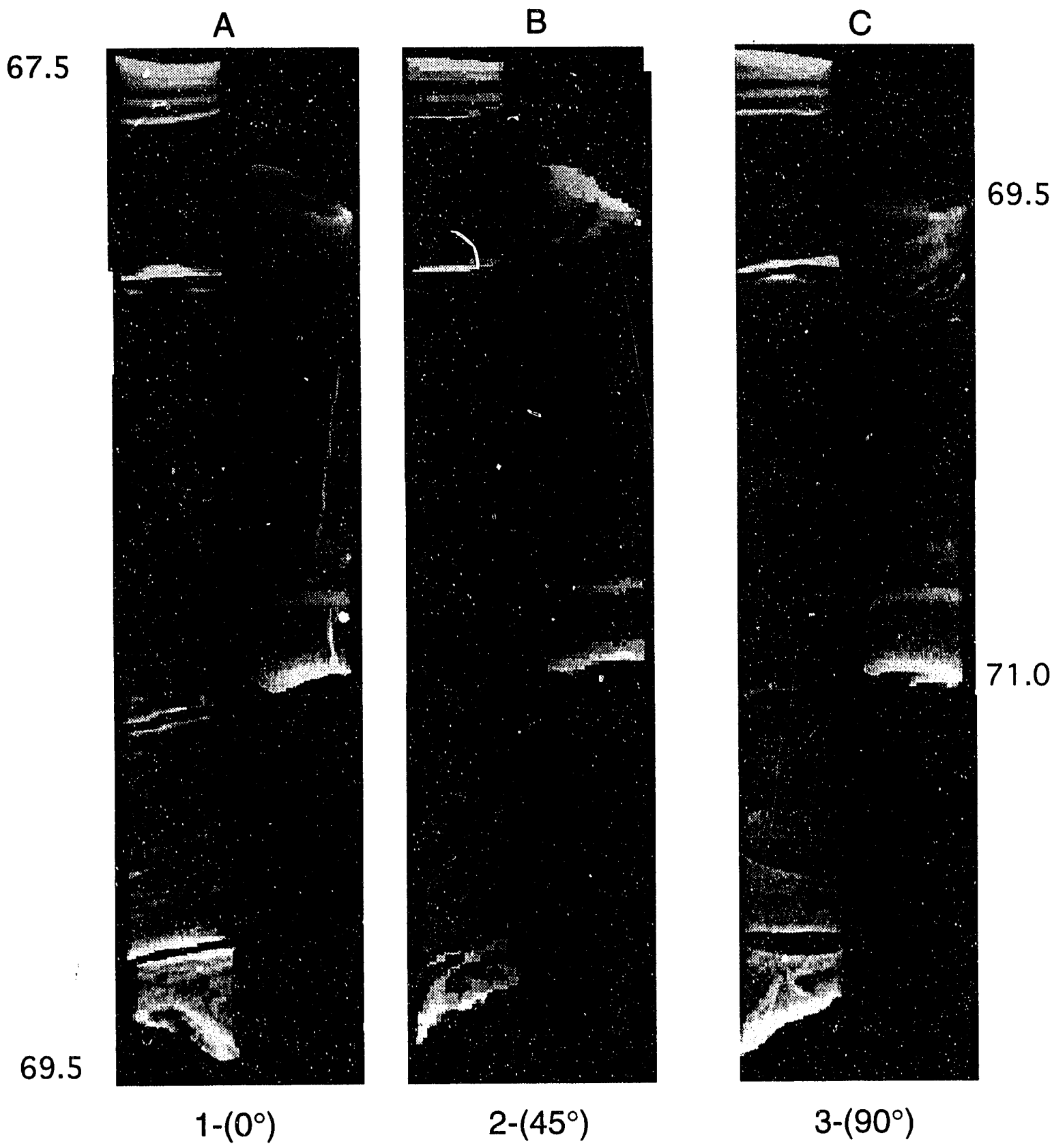

Fig. 1. Topogram of Bartlesville sandstone core. 


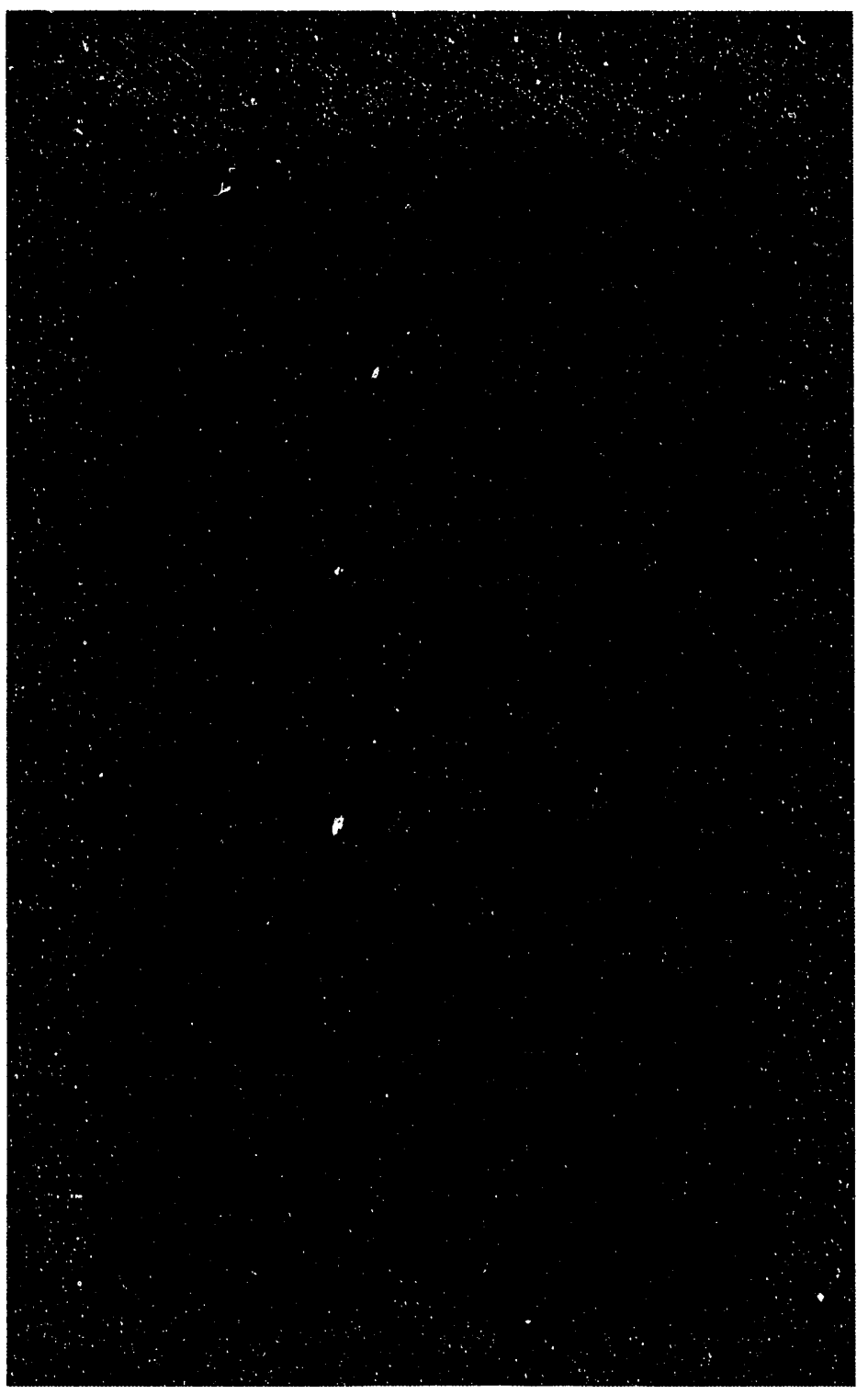

Fig. 2. Photograph of slabbed sandstone core showing healed fracture. 

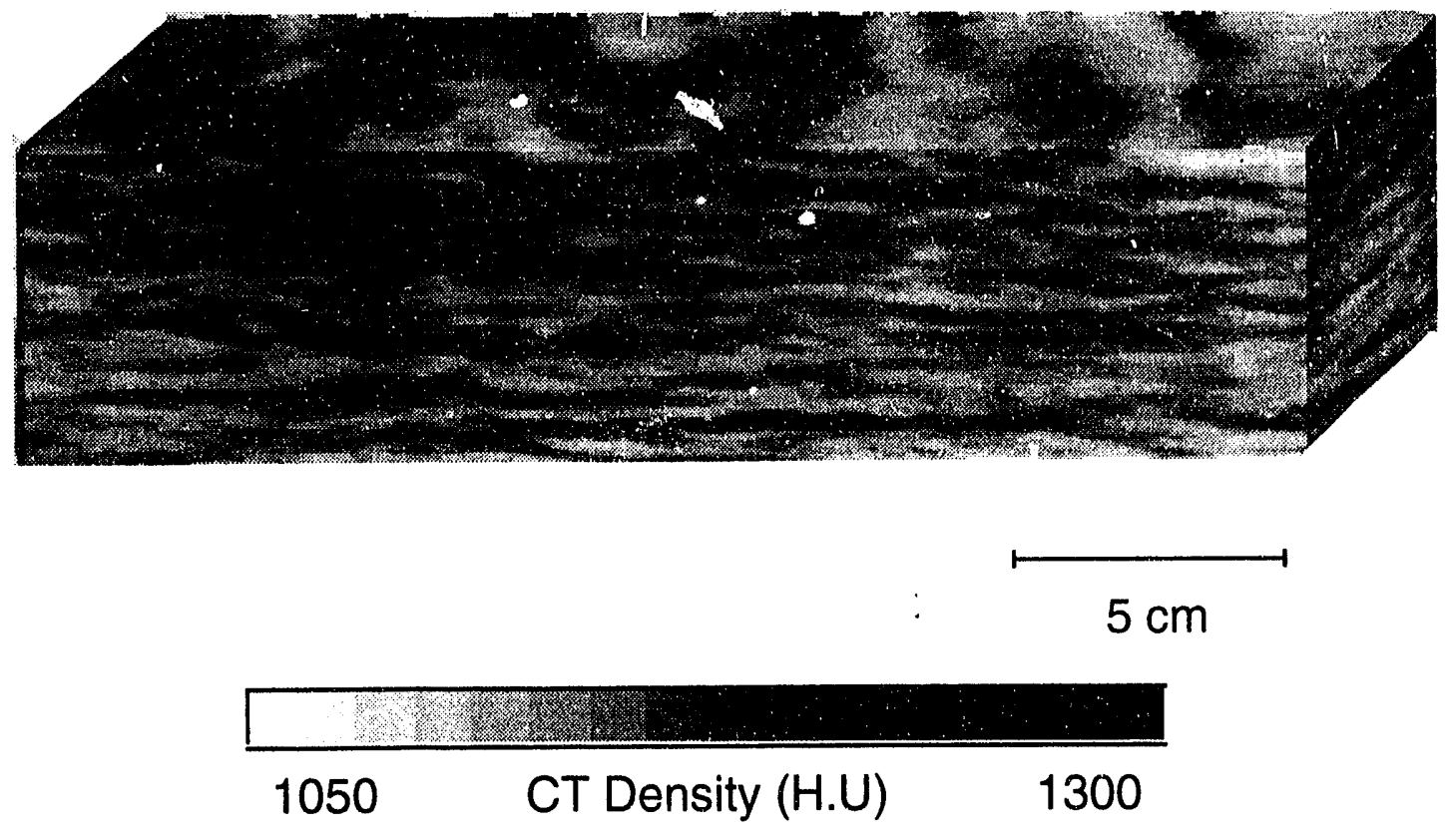

Fig. 3. Tallant sandstone block displaying climbing ripples. 

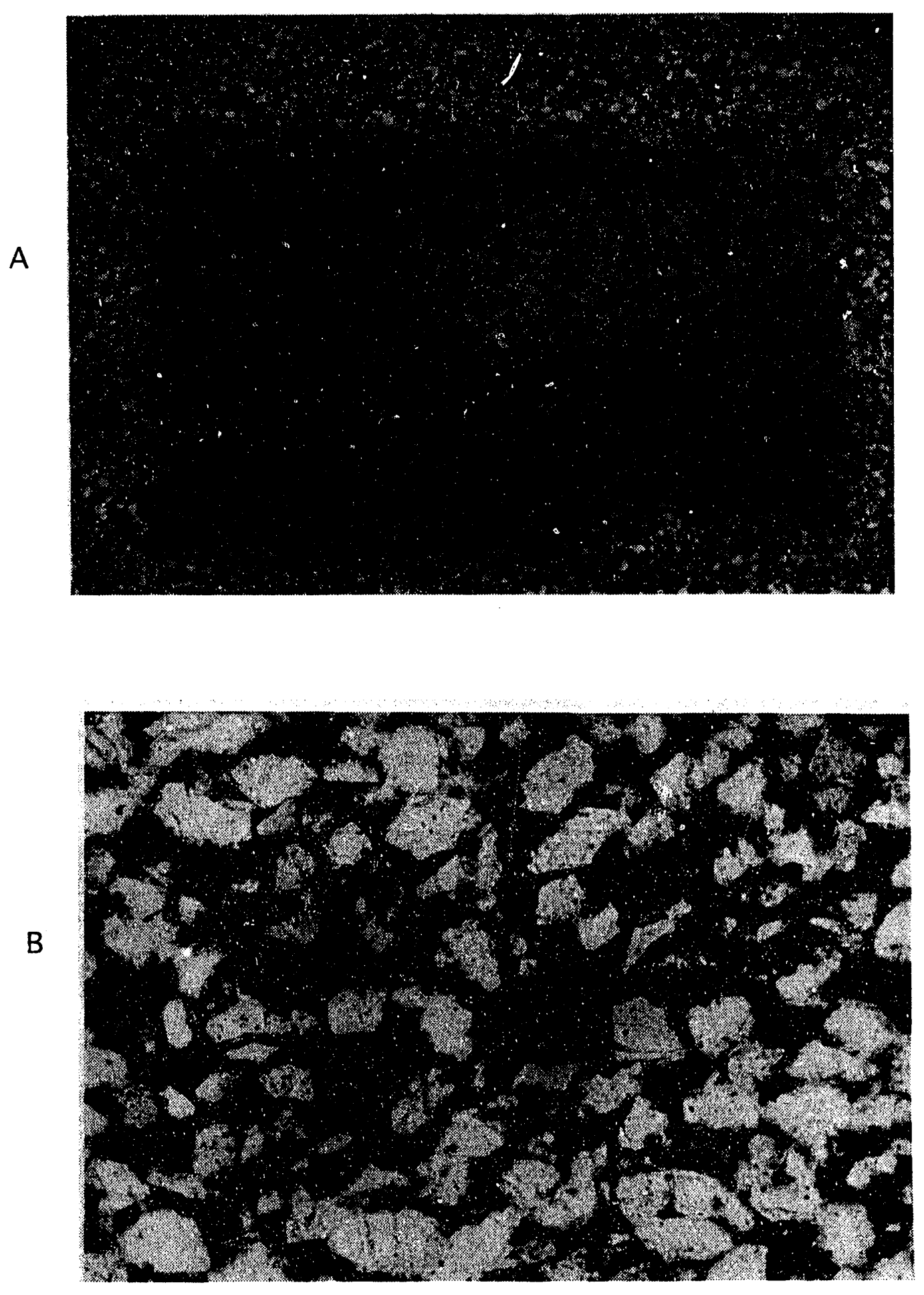

Fig. 4. Tallant sandstone Photomicrographs; A - Magnification: 15X. A low magnification view of a very fine-grained, very well-sorted, matrix-laminated, subarkosic sandstone with subparallel, arcuate matrix laminae. B - Magnification: $100 \mathrm{X}$. A detailed view of the laminar concentration of detrital clay matrix and abundant intergranular macro porosity within the sandstone flanking the matrix laminae. The pore network displays excellent interconnectivity, especially parallel to laminae. Scattered heavy minerals accompany the band of clay-rich sandstone. 

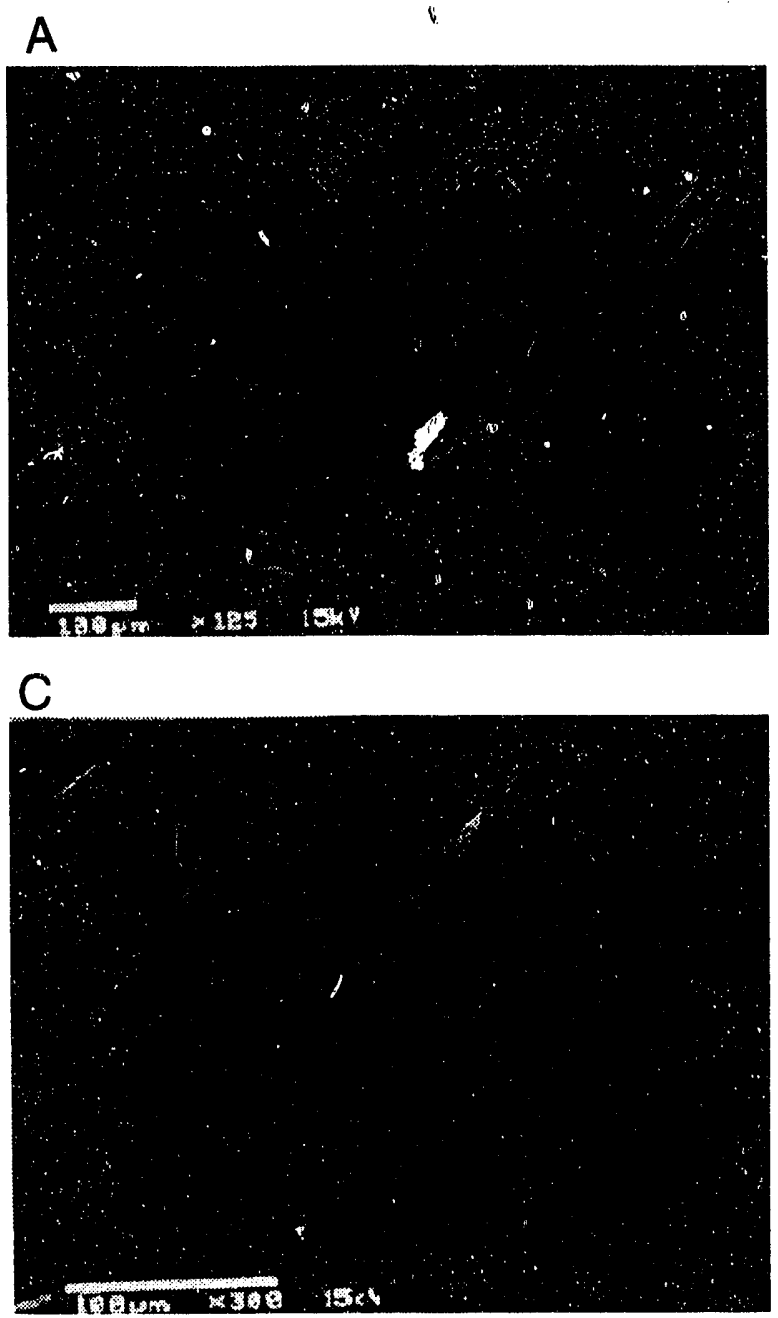

B

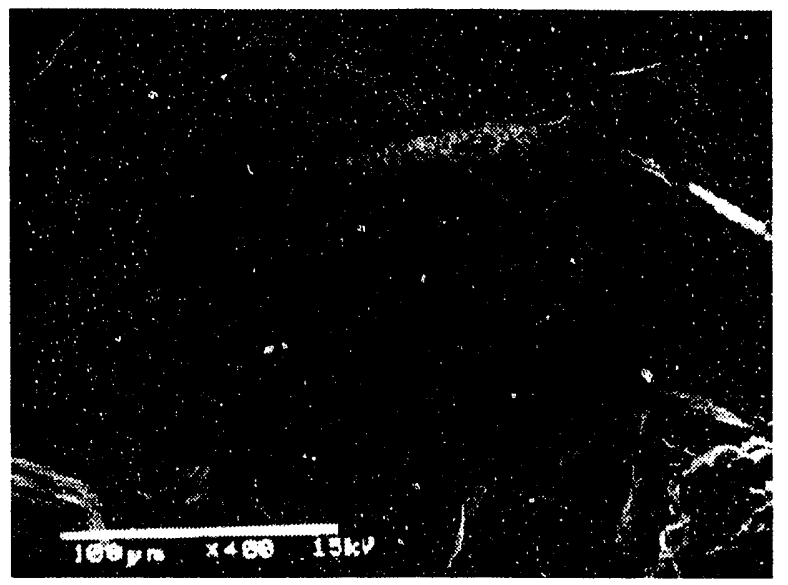

D

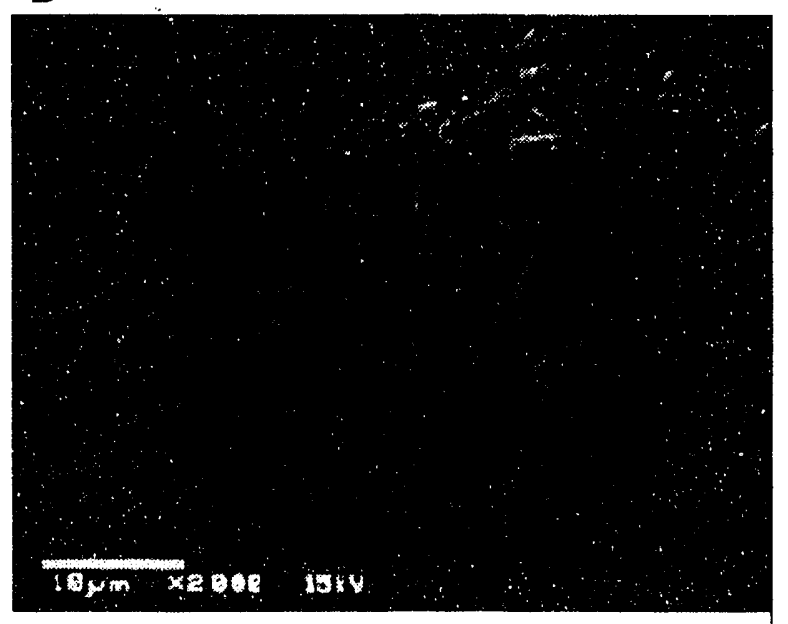

Fig. 5. Tallant sandstone SEM photomicrographs. A - Abundant intergranular macroporosity is distributed throught the figure; B - A partially disolved feldspar grain is displayed in the center of the figure; C - and D - illustrate a portion of the sandstone characterized by laminar concentrations of detrital and authigenic clay matrix. C - Clay matrix drapes detrital grain surfaces (center). D - Pore-filling clay consisting of a combination of kaolinite and illite is displayed. 


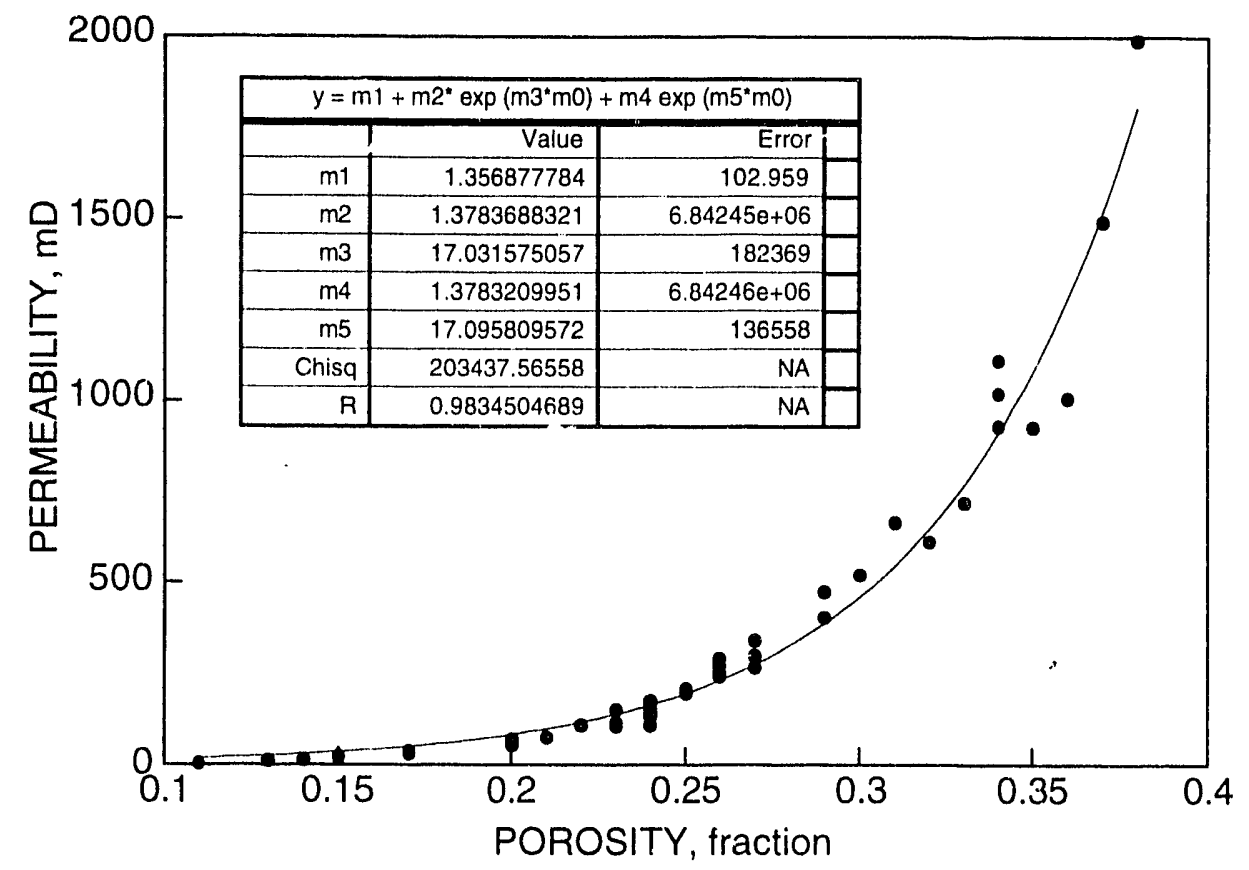

Fig. 6. Thin section derived permeability porosity correlation.

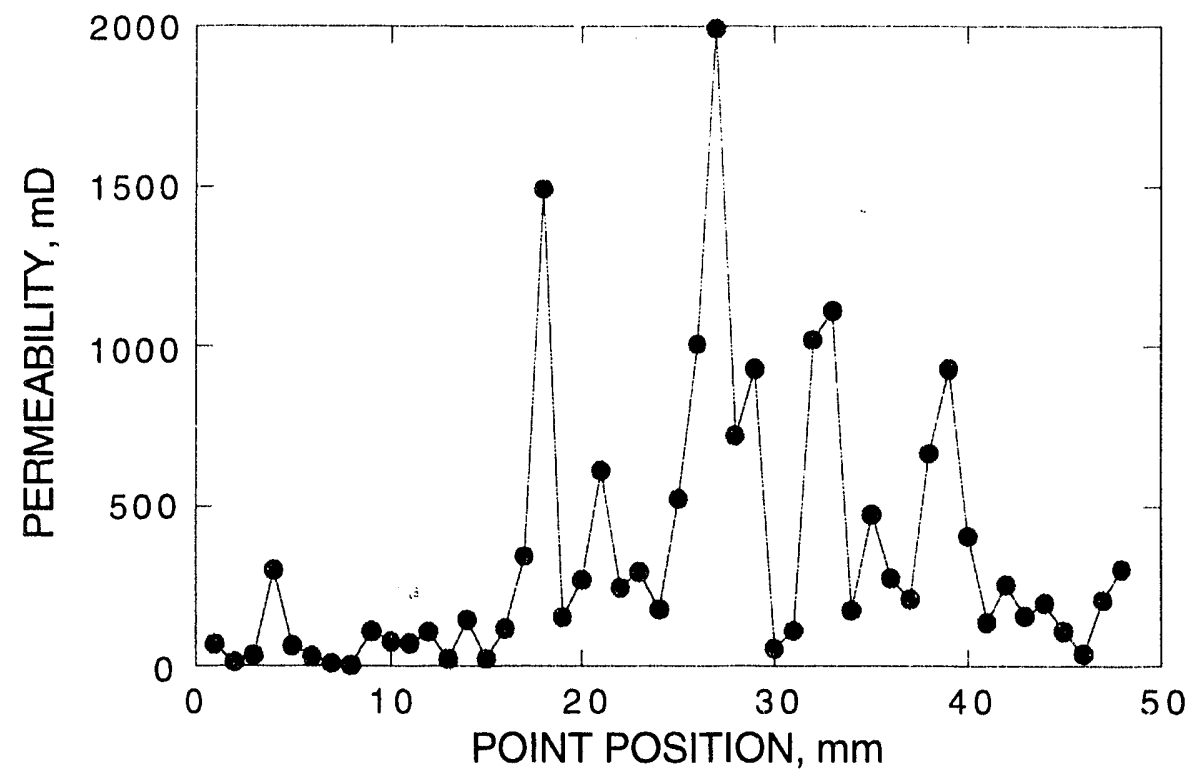

Fig. 7. Thin section image analysis derived permeability profile. 


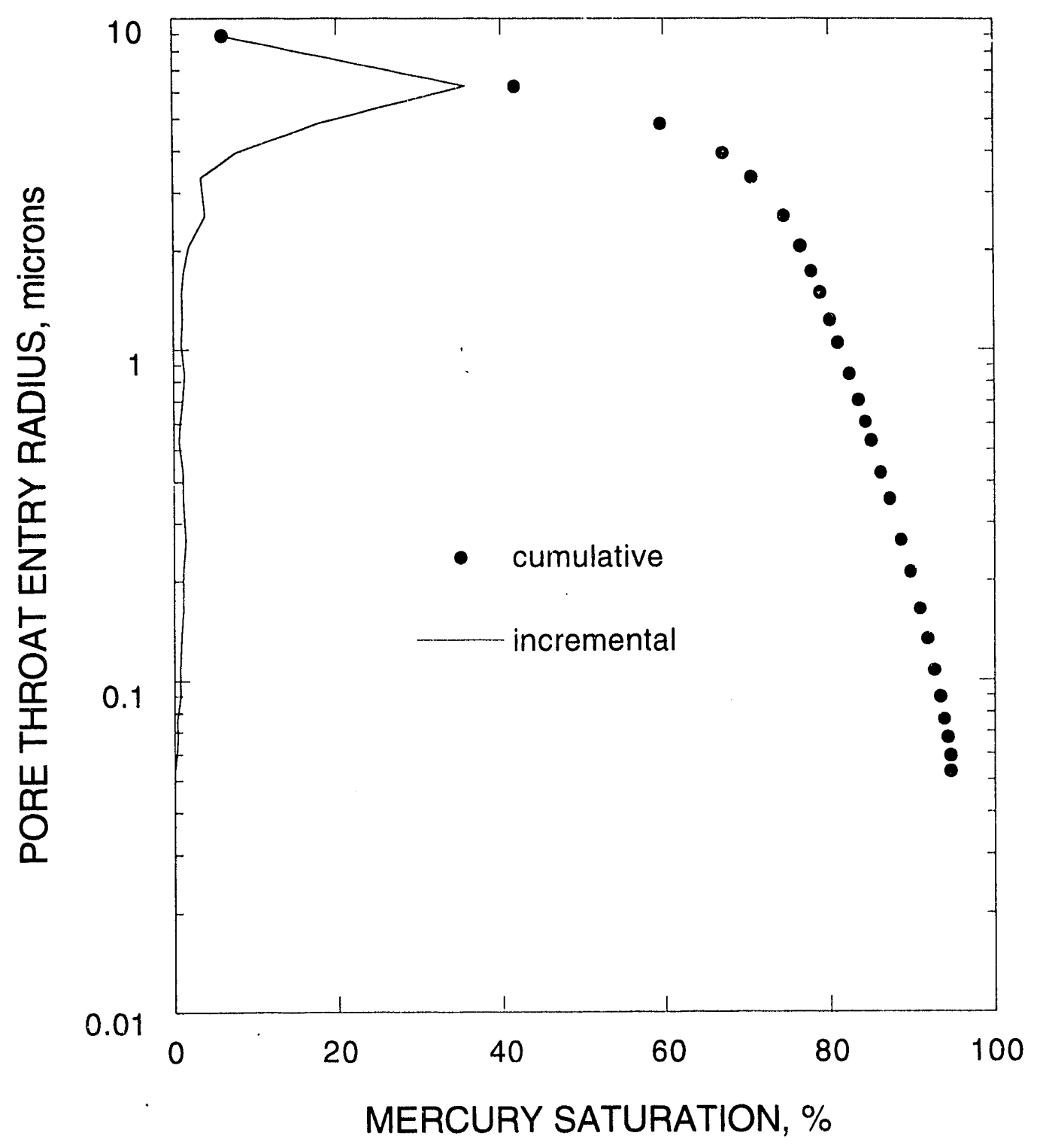

Fig. 8. Mercury intrusion pore throat size distribution. 


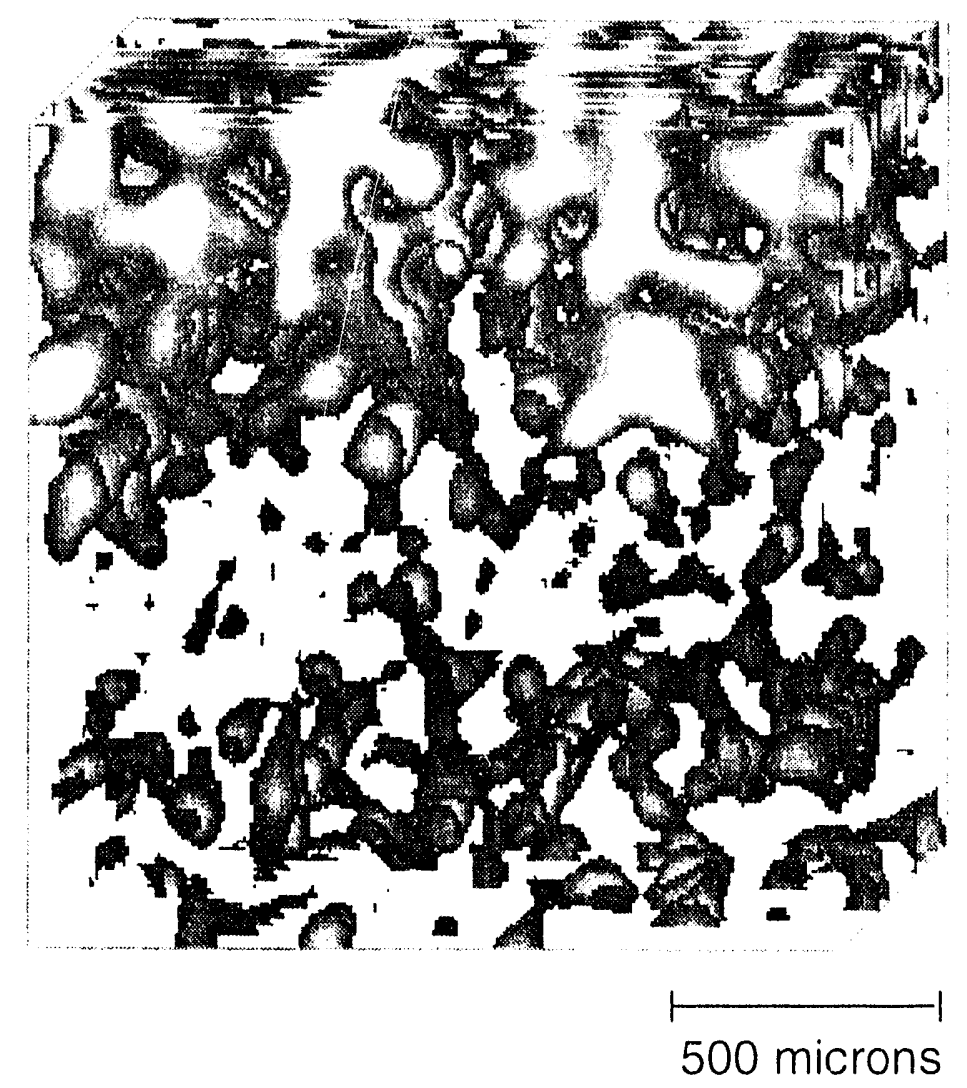

Fig. 9. NMRI microscop! image of pore network in Tallant sandstone microplug.

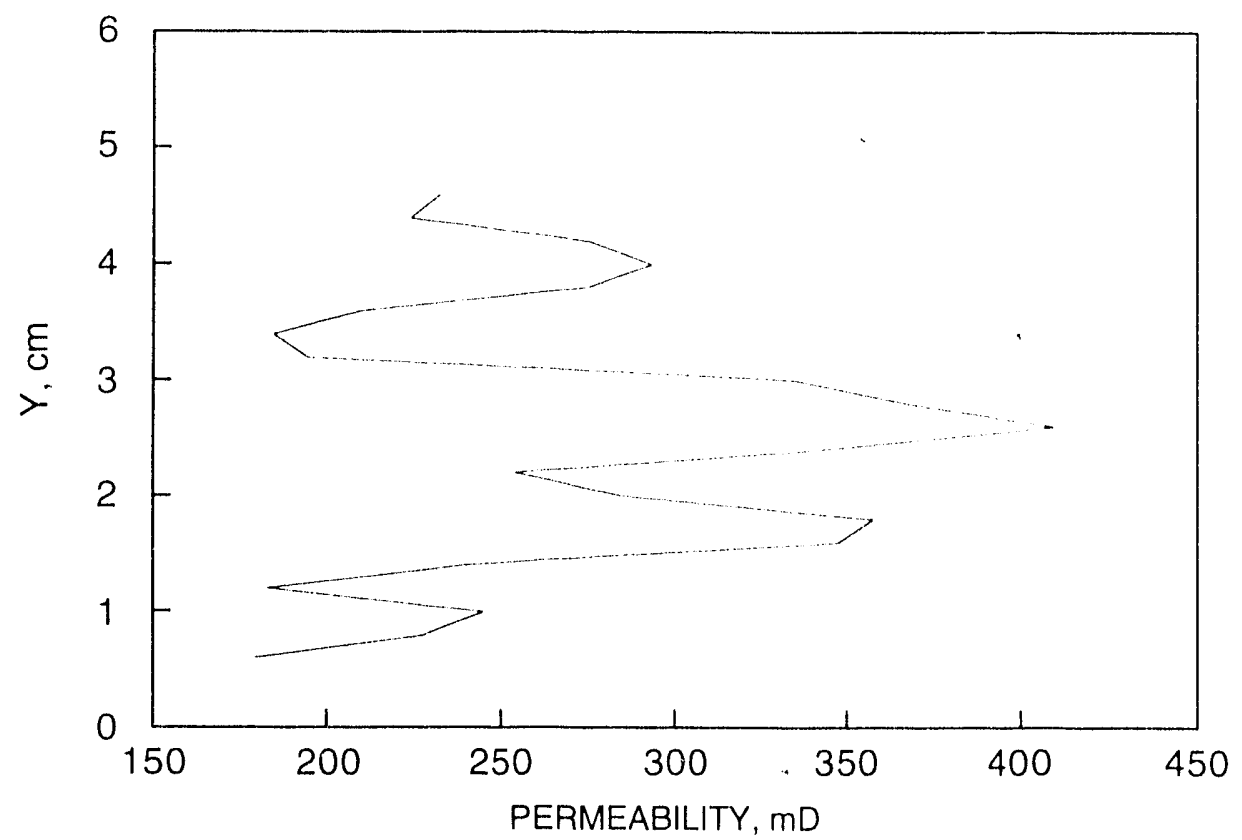

Fig. 10. Minipermeameter profïle across sample end. 

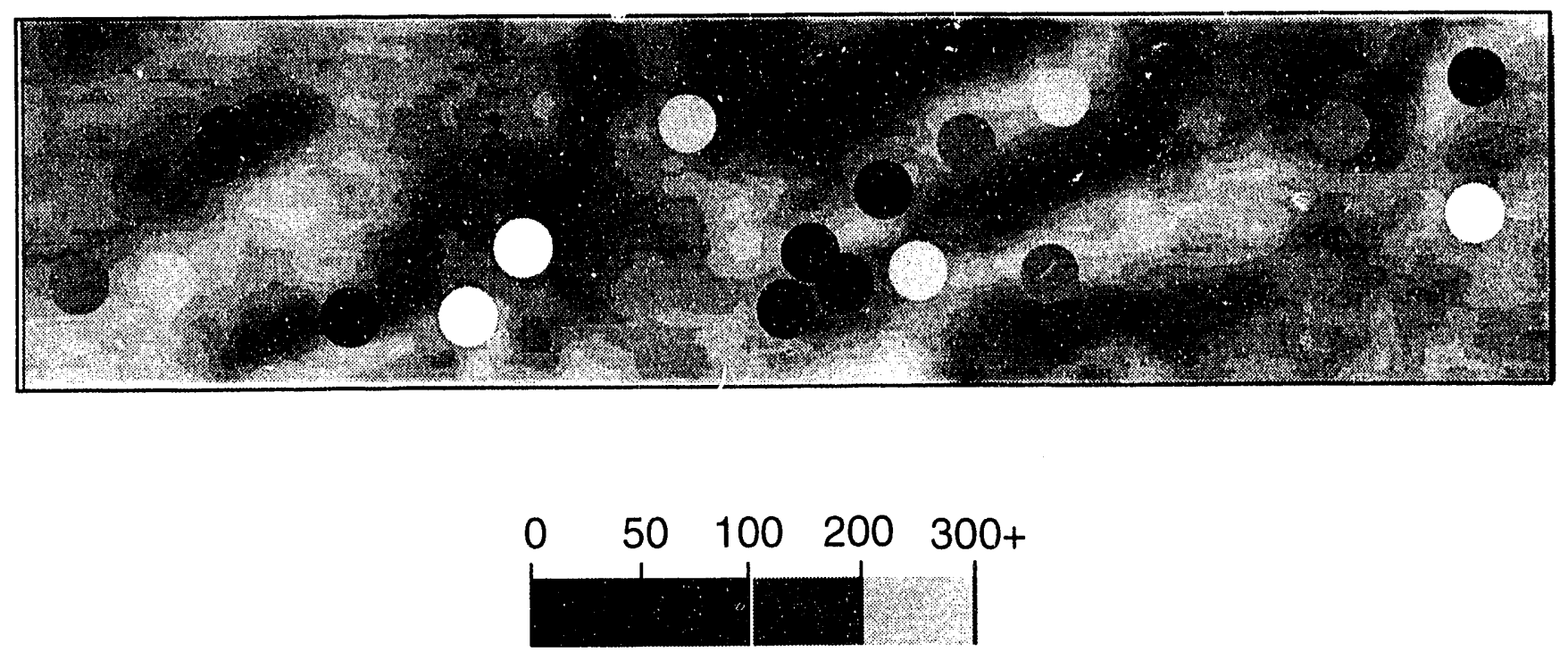

PERMEABILITY (mD)

Fig. 11. Minipermeameter values along side where laminations intersect the surface at a small angle. 

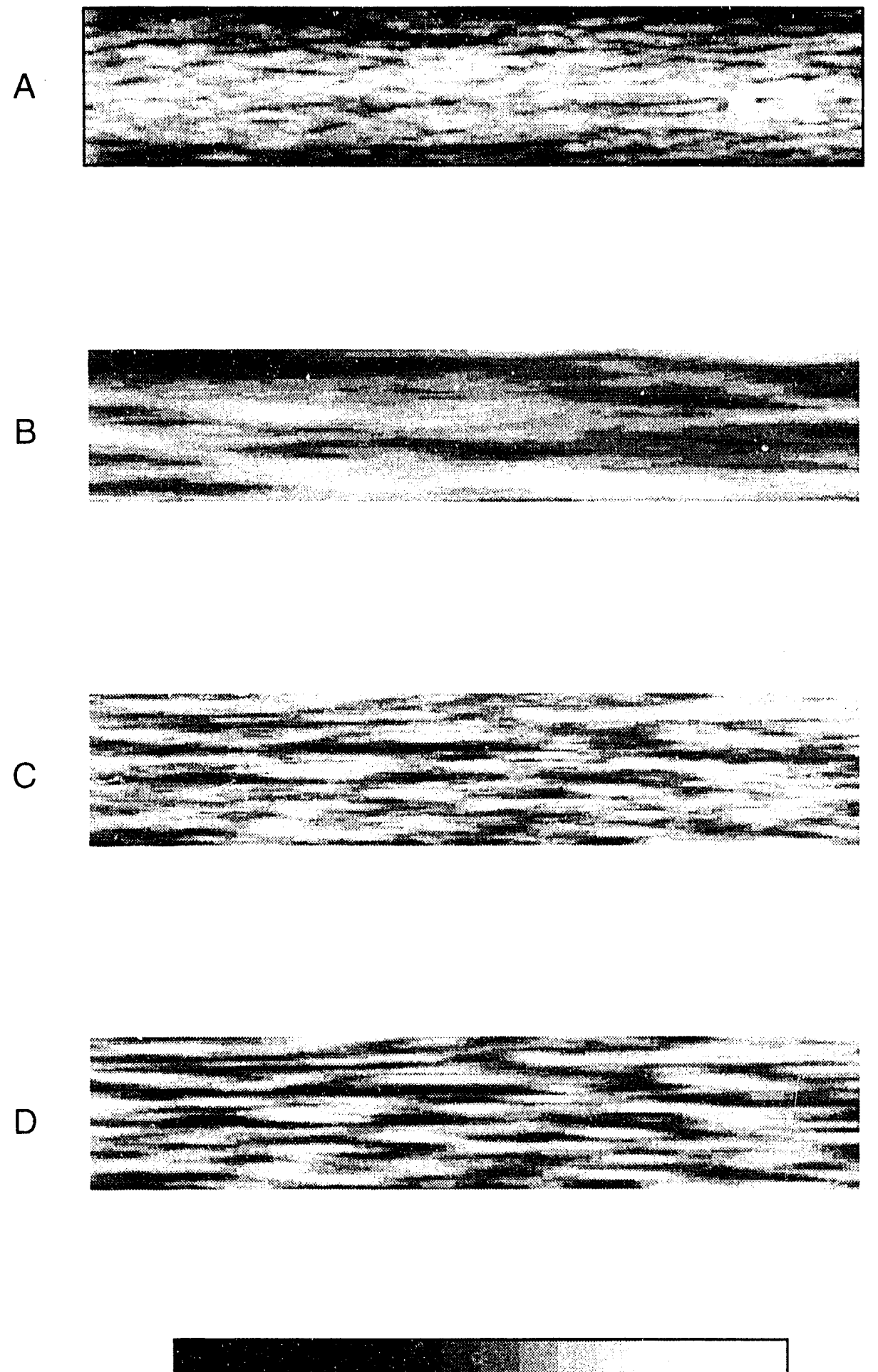

18 POROSITY (PERCENT) 30

Fig. 12. Porosity distribution in a vertical/longitudinal plane: $A$ - from CT; B - Turning Bands Bessel Porosity; C - Turning Banks Exponent Porosity; D - Turning Banks Gaussian Porosity'. 

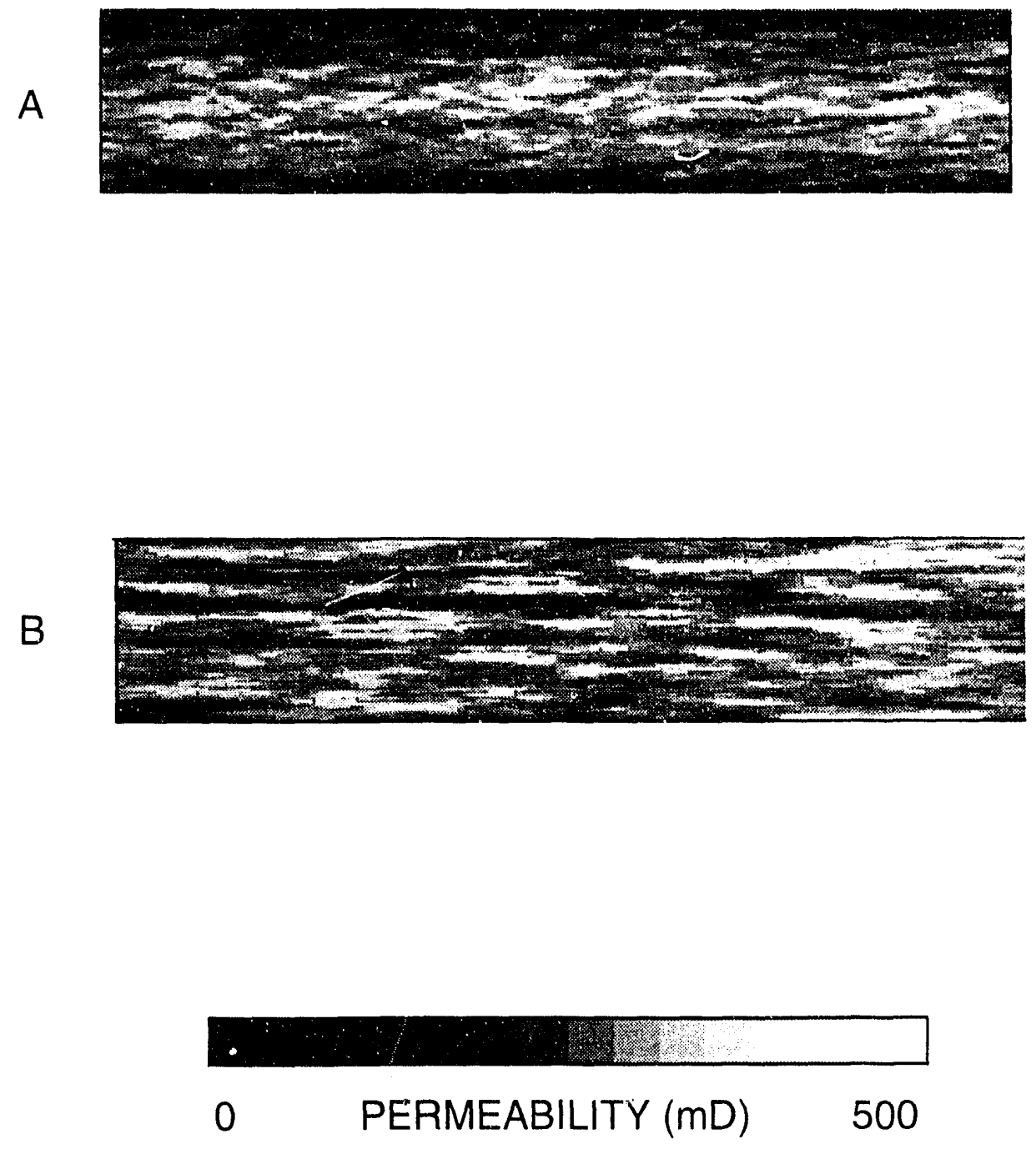

Fig. 13. Permeability distribution in a vertical/longitudinal plane: A - Tallant CT Permeability; B - Turning Bands Exponent Permeability. 

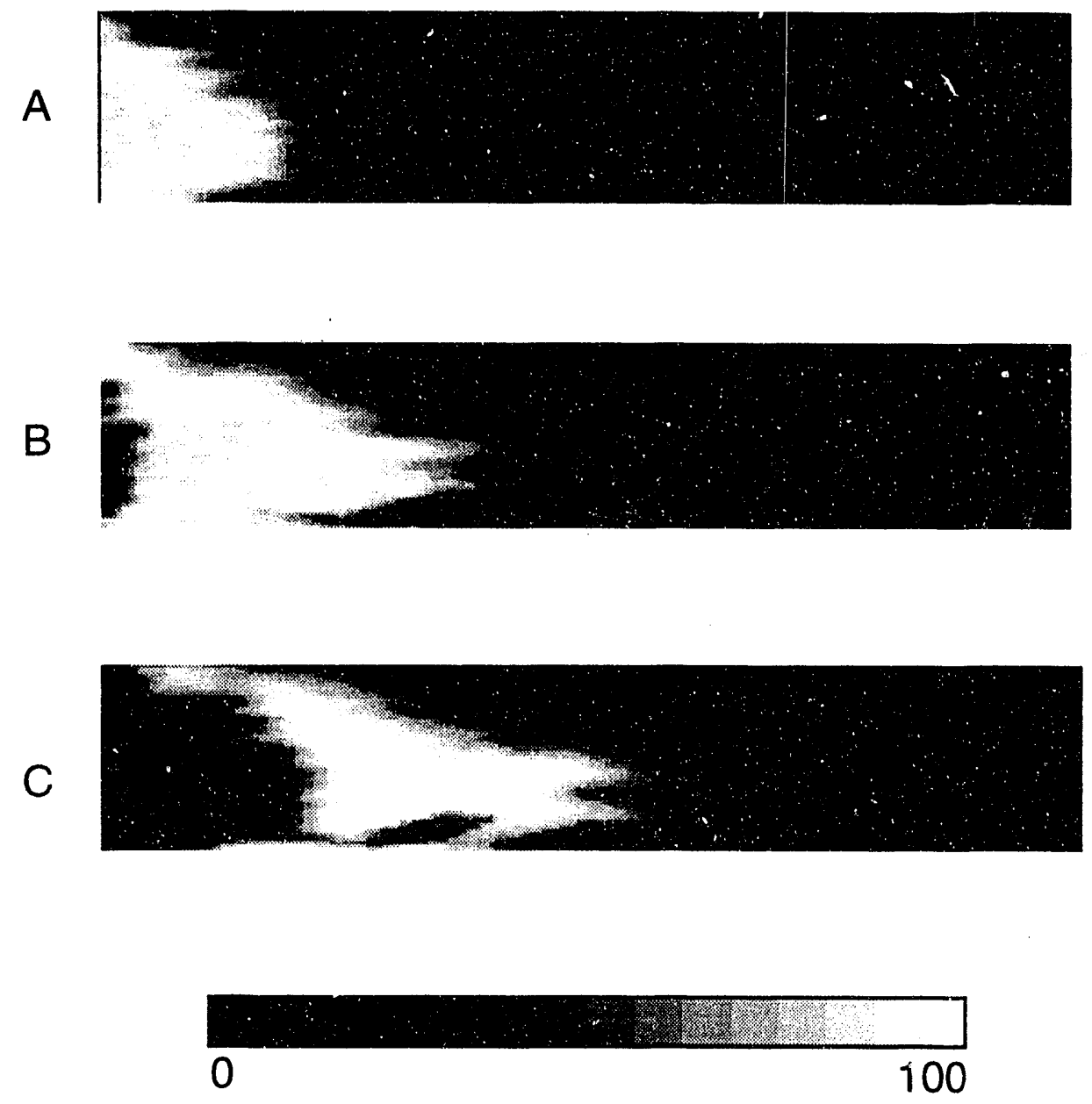

TAGGED BRINE CONCENTRATION (\%)

Fig. 14. Tracer test observed by $C T$ image shows fine fingering due to the permeability contrast: A - 0.1 pore volume; $B-0.26$ pore volume; $C-0.39$ pore volune. 

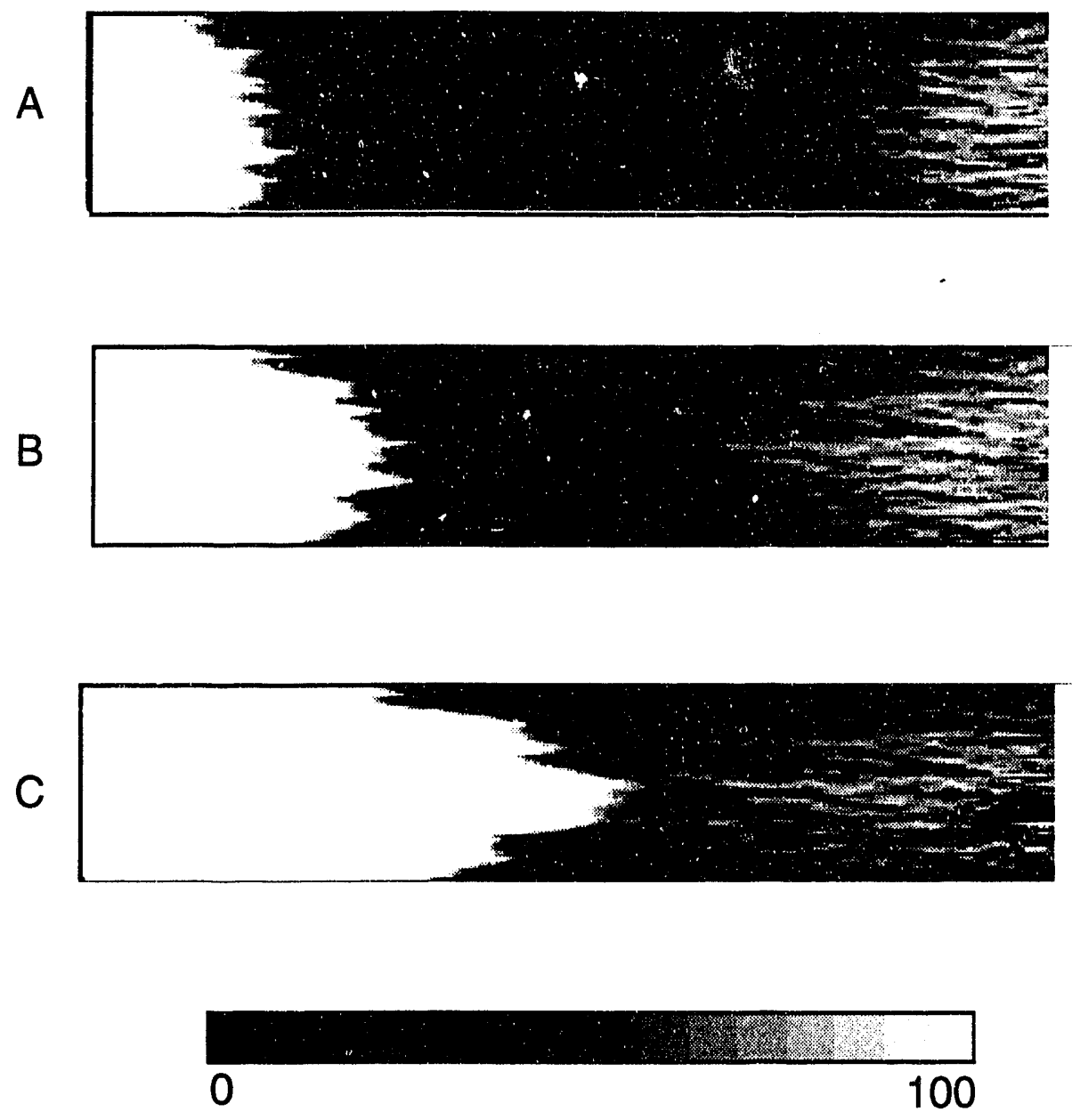

TAGGED BRINE CONCENTRATION (\%)

Fig. 15. Tracer test simulation using $C T /$ thin section image analysis data: $A-0.15$ pore volume; $B-0.26$ pore volume; C - 0.41 pore volume. 

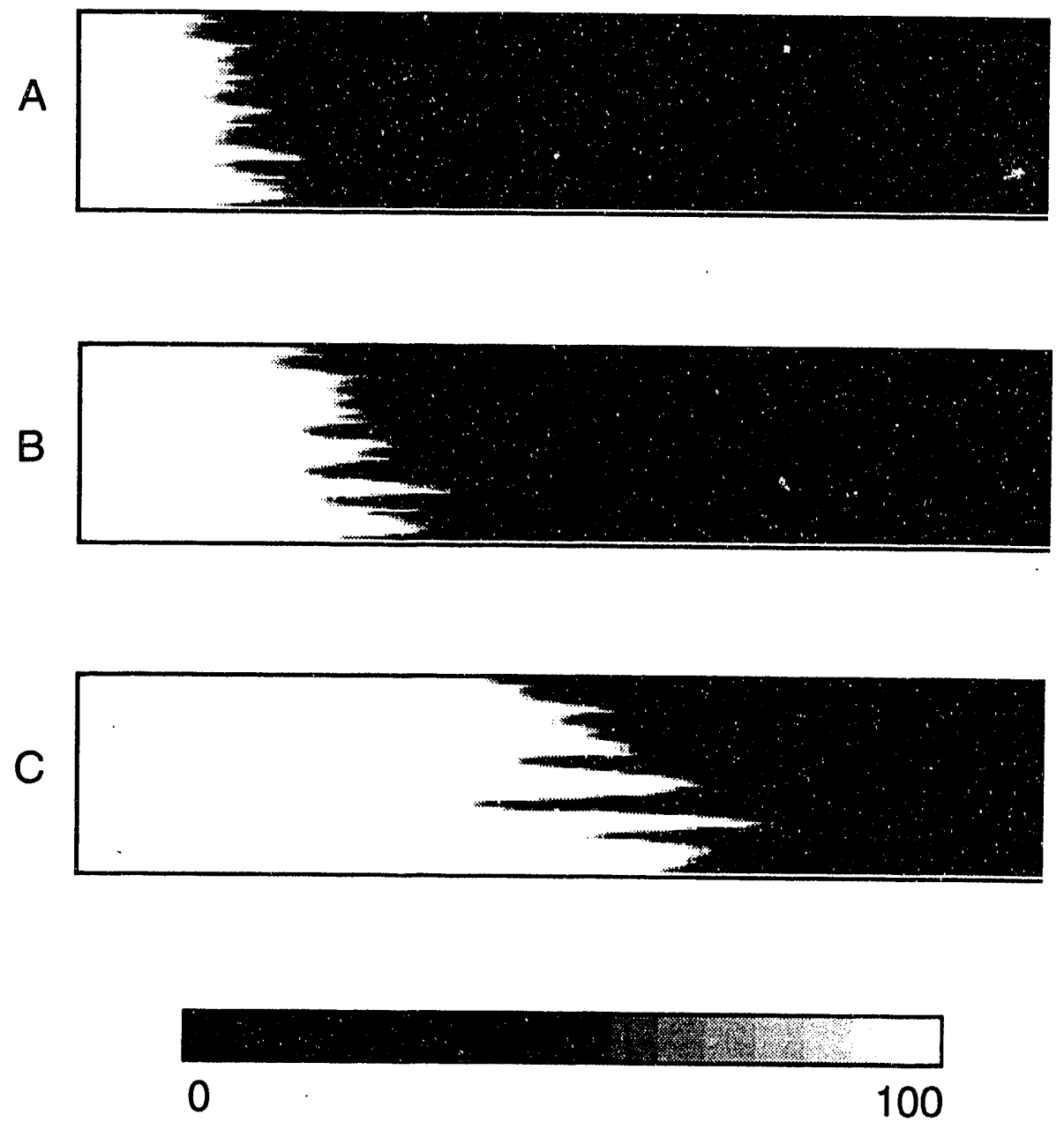

TAGGED BRINE CONCENTRATION (\%)

Fig. 16. Tracer test simulation using Turning Bands generated data: A - 0.15 pore volume; $\mathrm{B}$ - pore volume; C -0.5 pore volume 

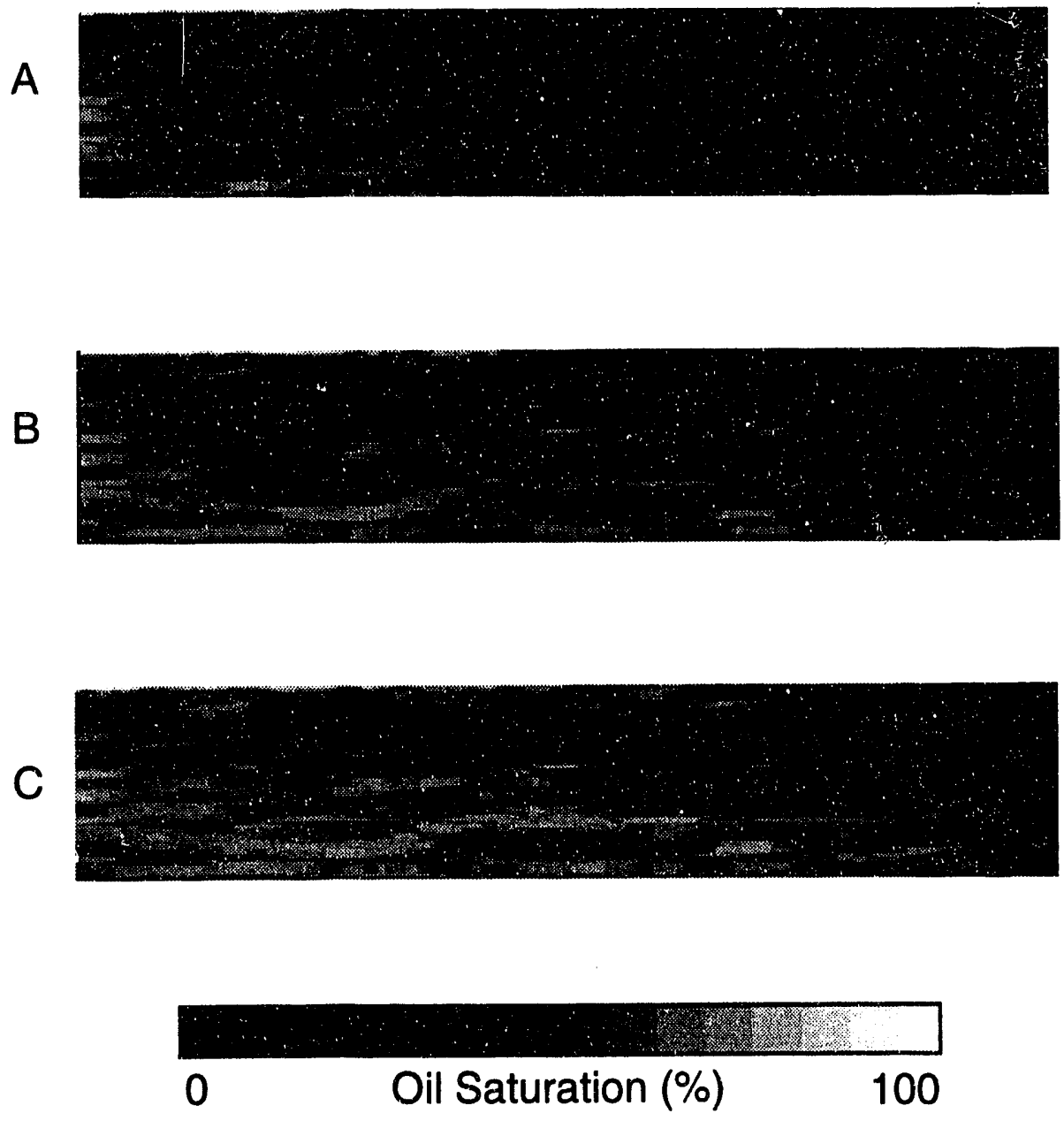

Fig. 17. Oil flood (1cp) of $100 \%$ brine saturated Tallant sandstone sample. - CT measurements: A - 0.10 pore volume; $\mathrm{B}-0.32$ pore volume; $\mathrm{C}-\mathbf{0 . 4 2}$ pore volume. 

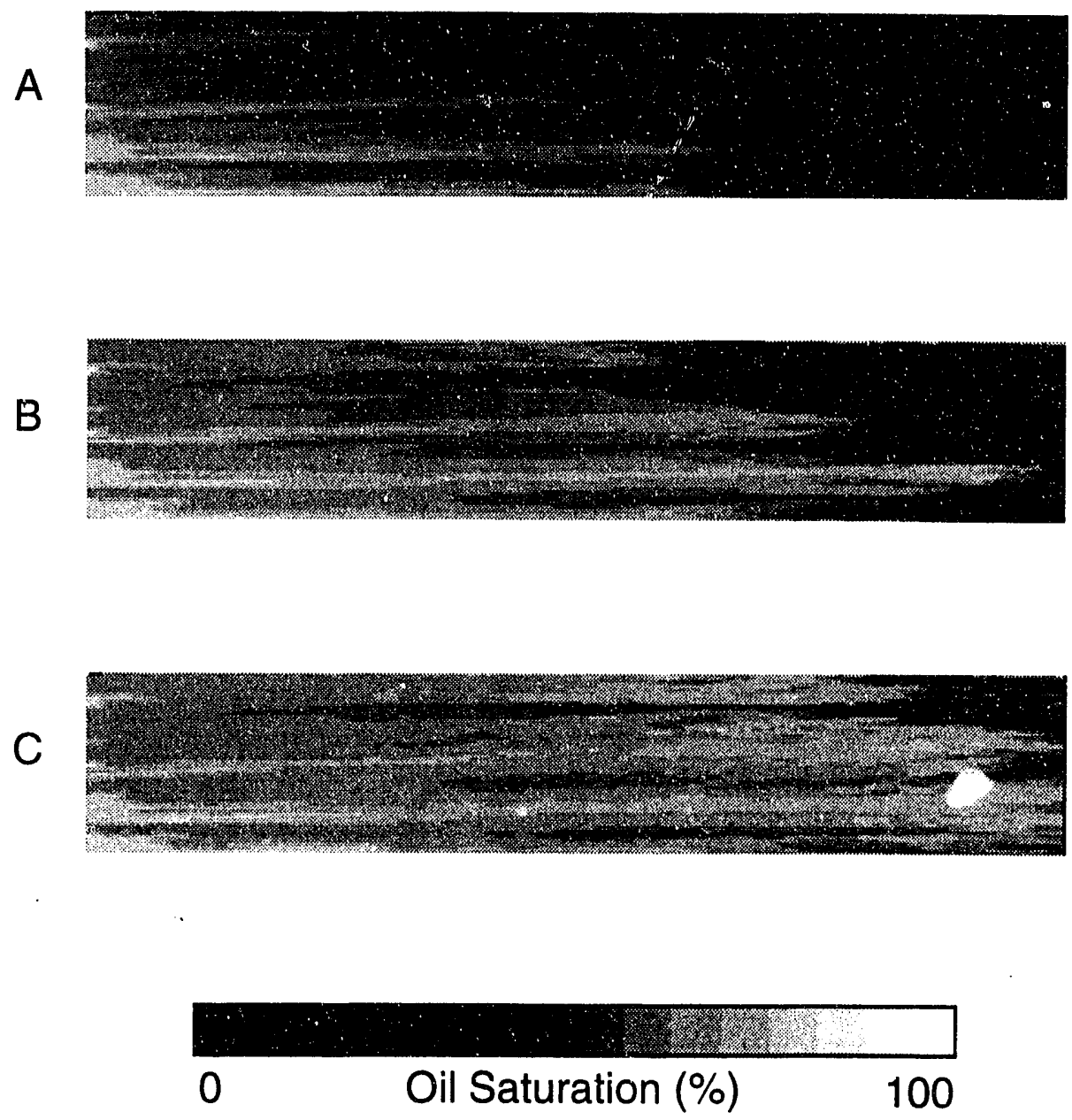

Fig. 18. Oil flood (1cp) of $100 \%$ brine saturated Tallant sandstone sample. - Simulation using CT/thin section image analysis data: $\mathrm{A}-0.26$ pore volume; $\mathrm{B}-0.43$ pore volume; $C-0.51$ pore volume. 

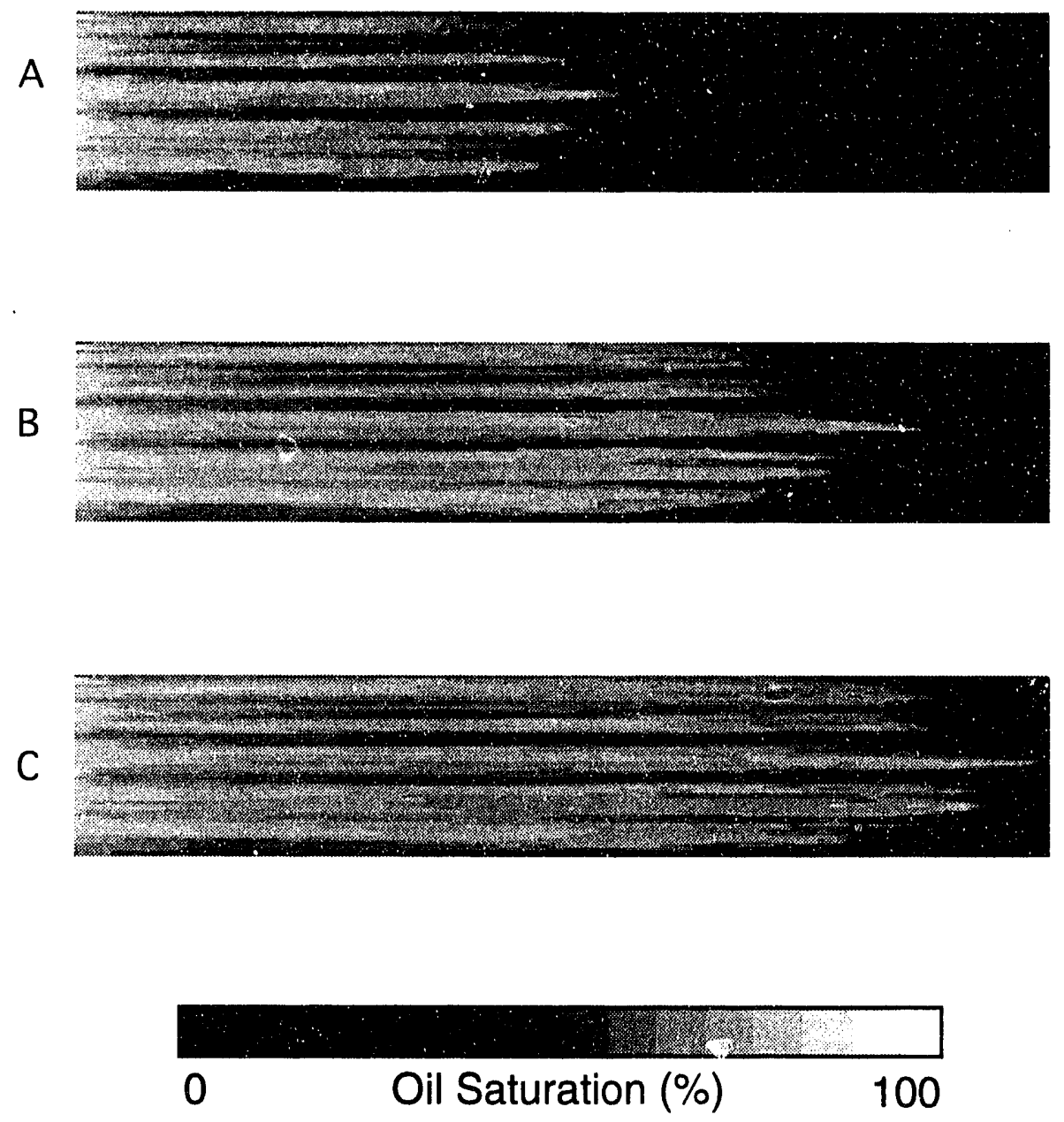

Fig. 19. Oil flood (1cp) of $100 \%$ brine saturated Tallant sandstone sample. - Simulation using Turning Bands generated data: A - 0.26 pore volume; $\mathrm{B}-0.43$ pore volume; $\mathrm{C}-0.51$ pore volume. 


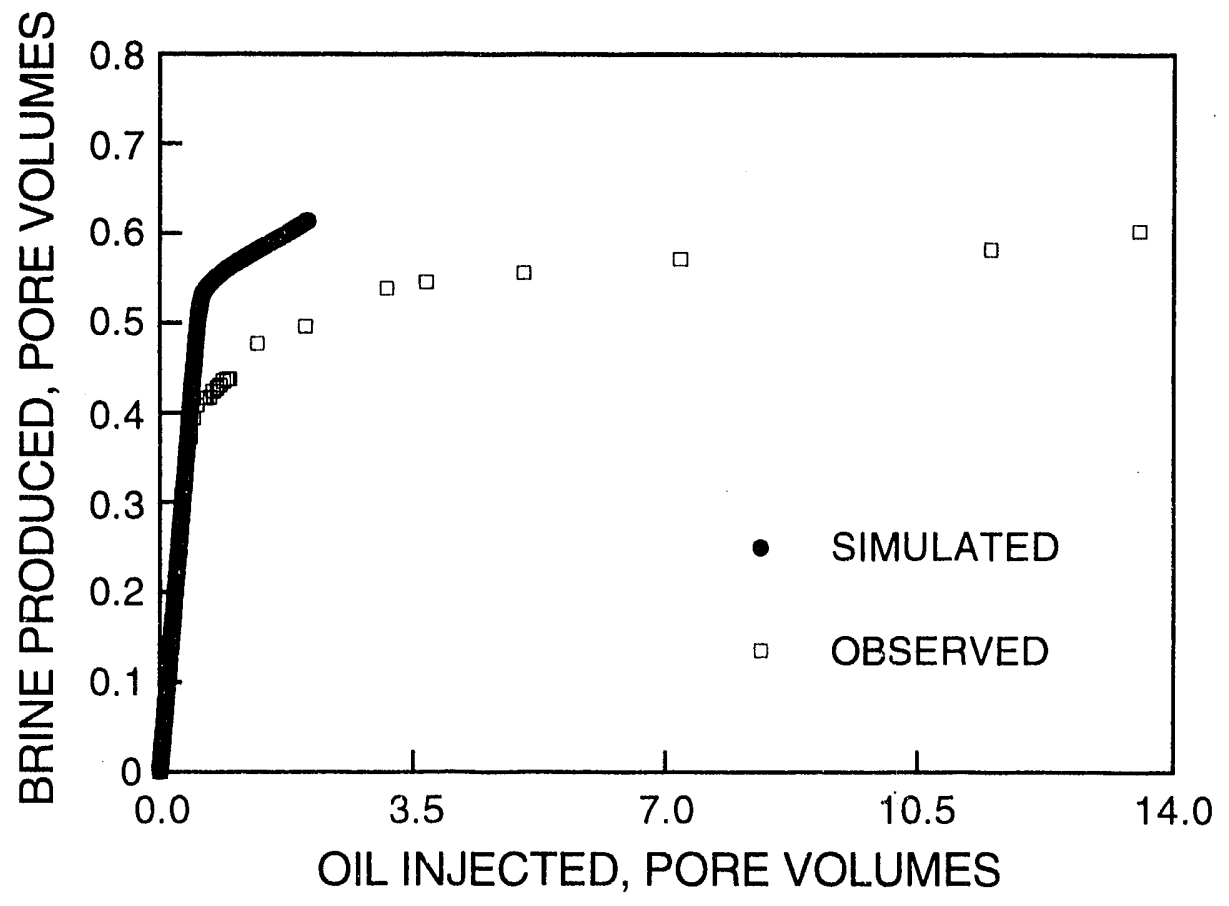

Fig. 20. Brine production curves, Icp oil. 

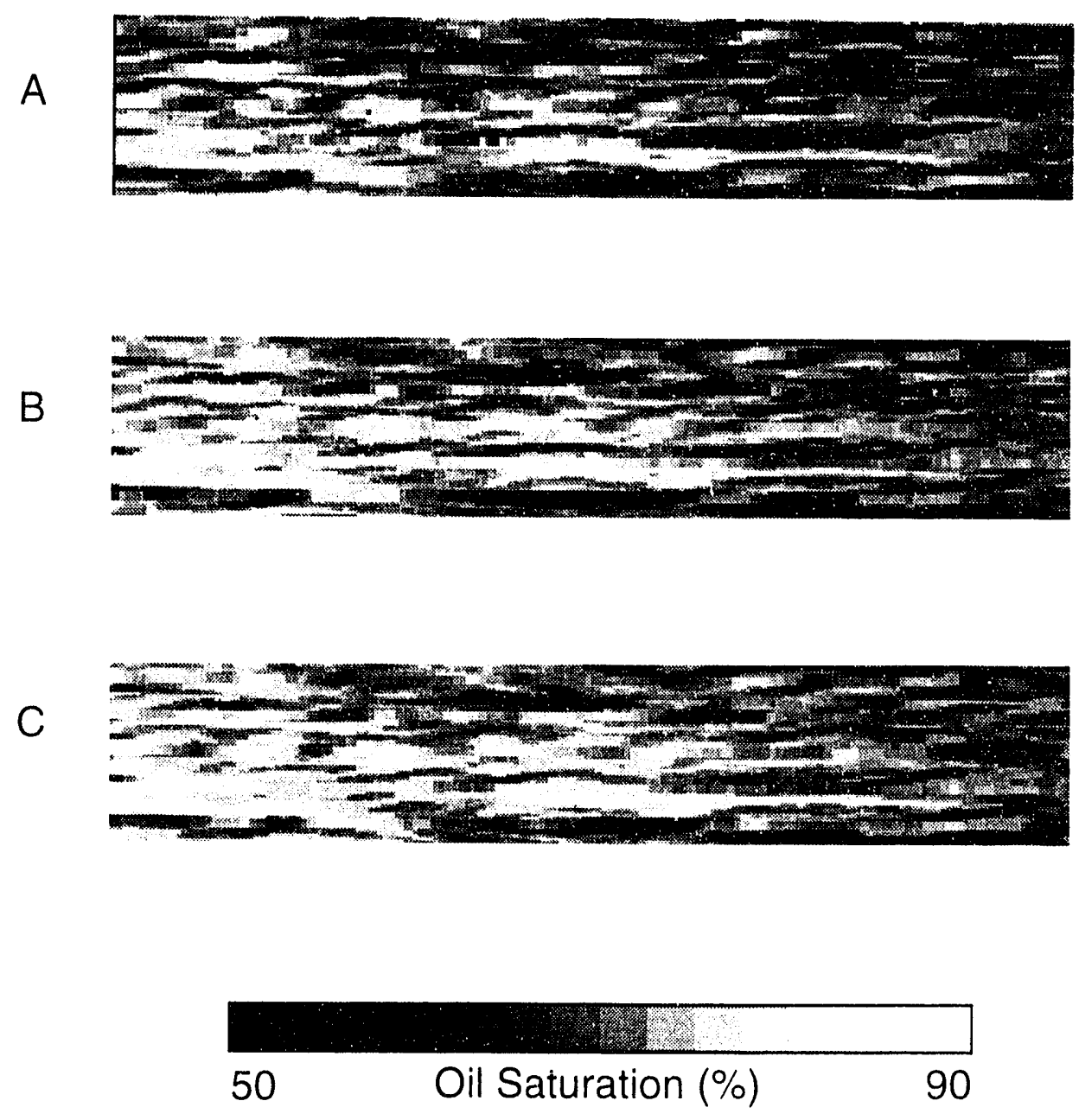

Fig. 21. Oil saturation distributions at residual brine (CT measurements): A $1 \mathrm{cp}$ oil; $B-2.3 \mathrm{cp}$ oil ; $-26 \mathrm{cp}$ oil. 


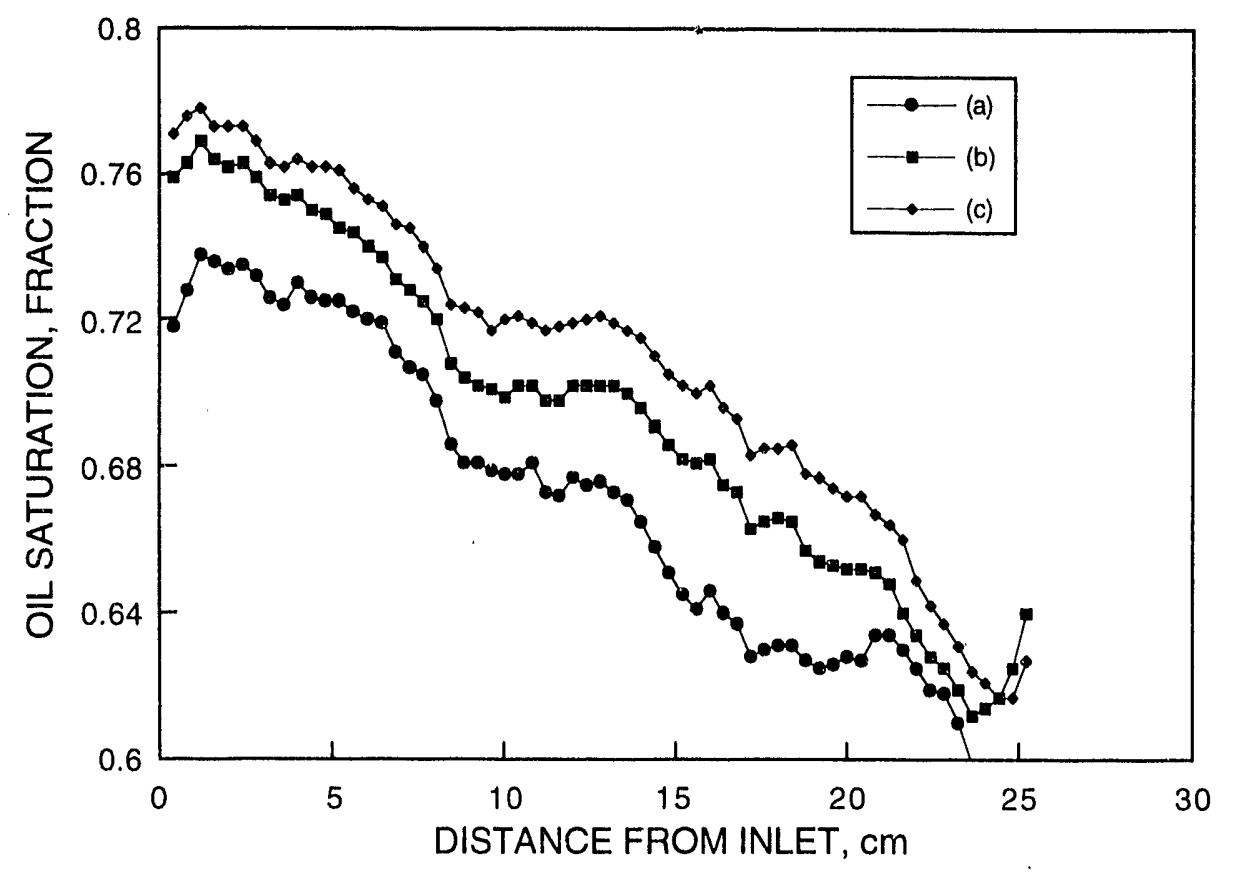

Fig. 22. Average oil saturation longitudinal profile at residual brine (CT measurements):A - Icp oil; B $-2.6 \mathrm{cp}$ oil; C $-23 \mathrm{cp}$ oil.

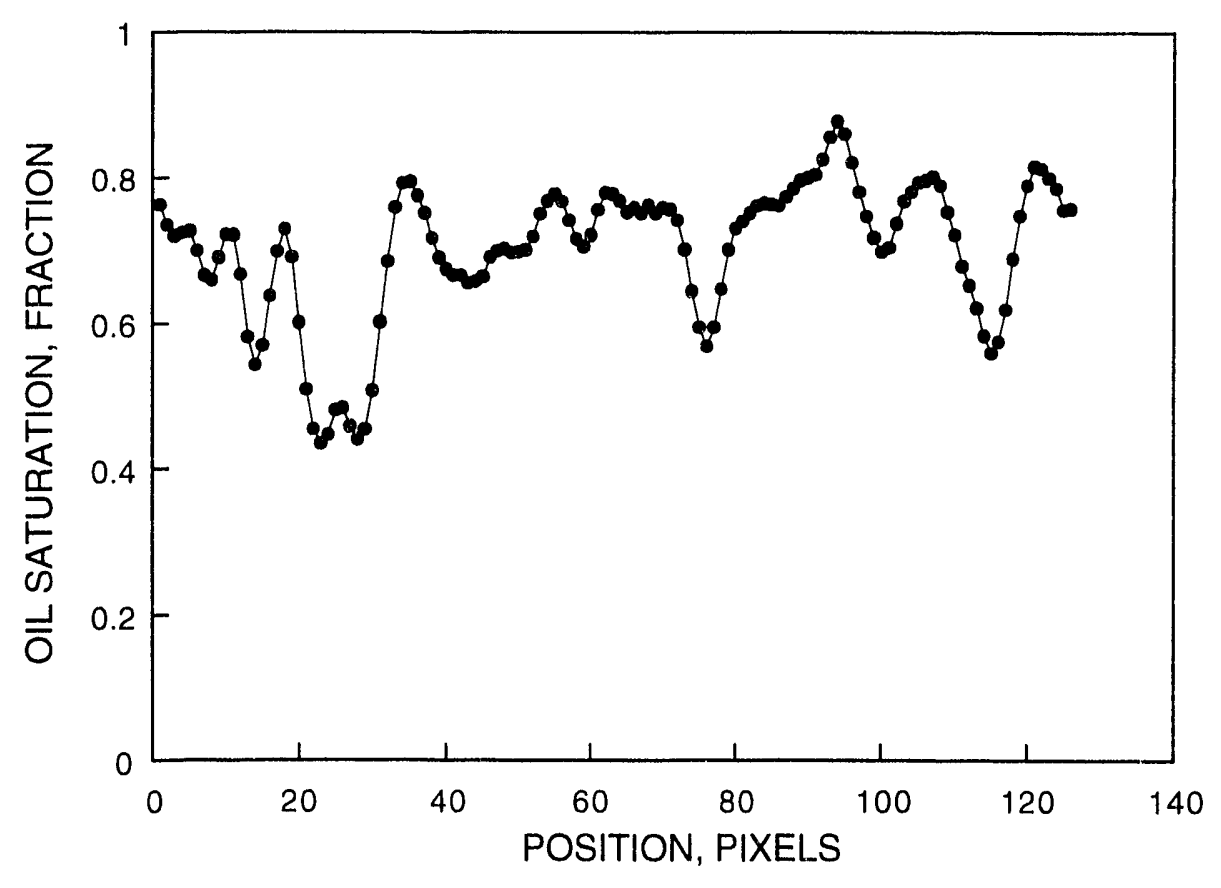

Fig. 23. Vertical protile of oil saturation at residual brine (CT measurements): $(2.6 \mathrm{cP}$ oil $)$. 


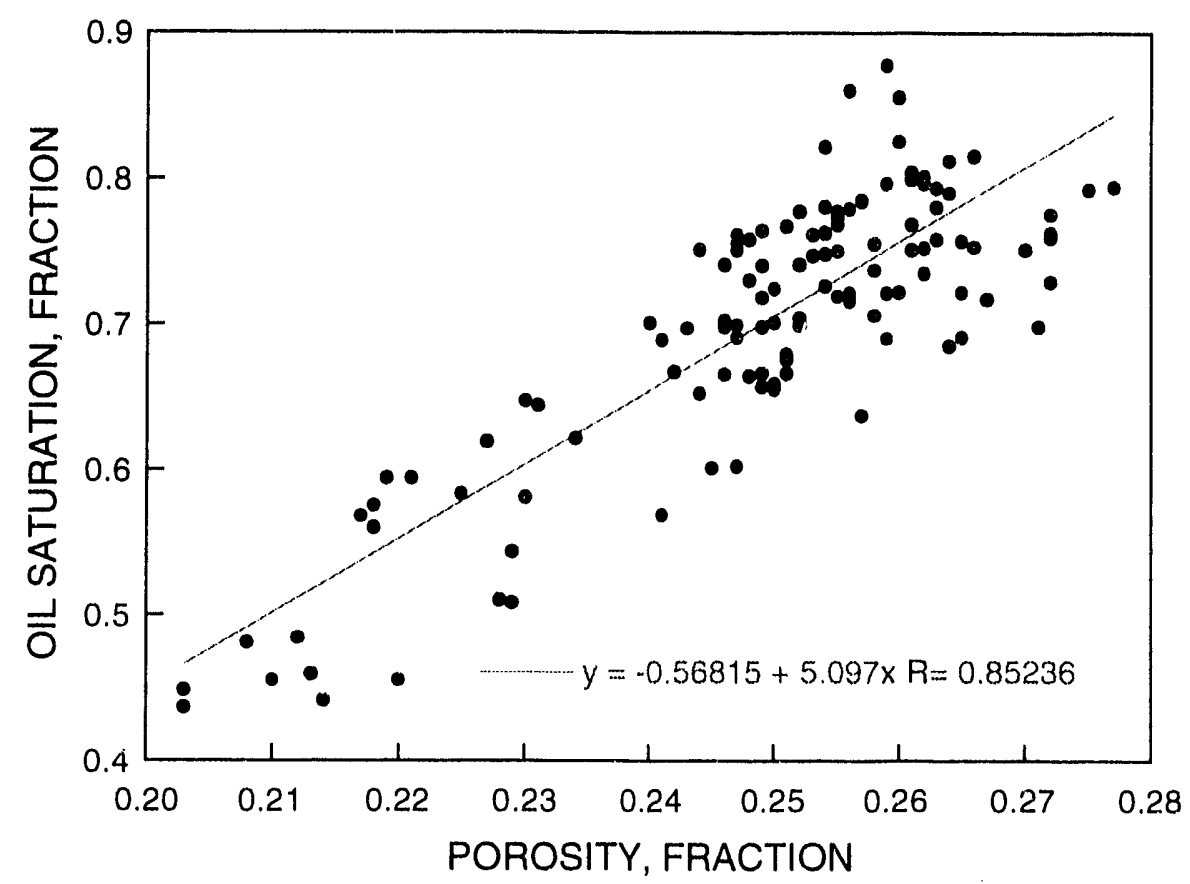

Fig. 24. Correlation of oil saturation at residual brine vs. porosity. 

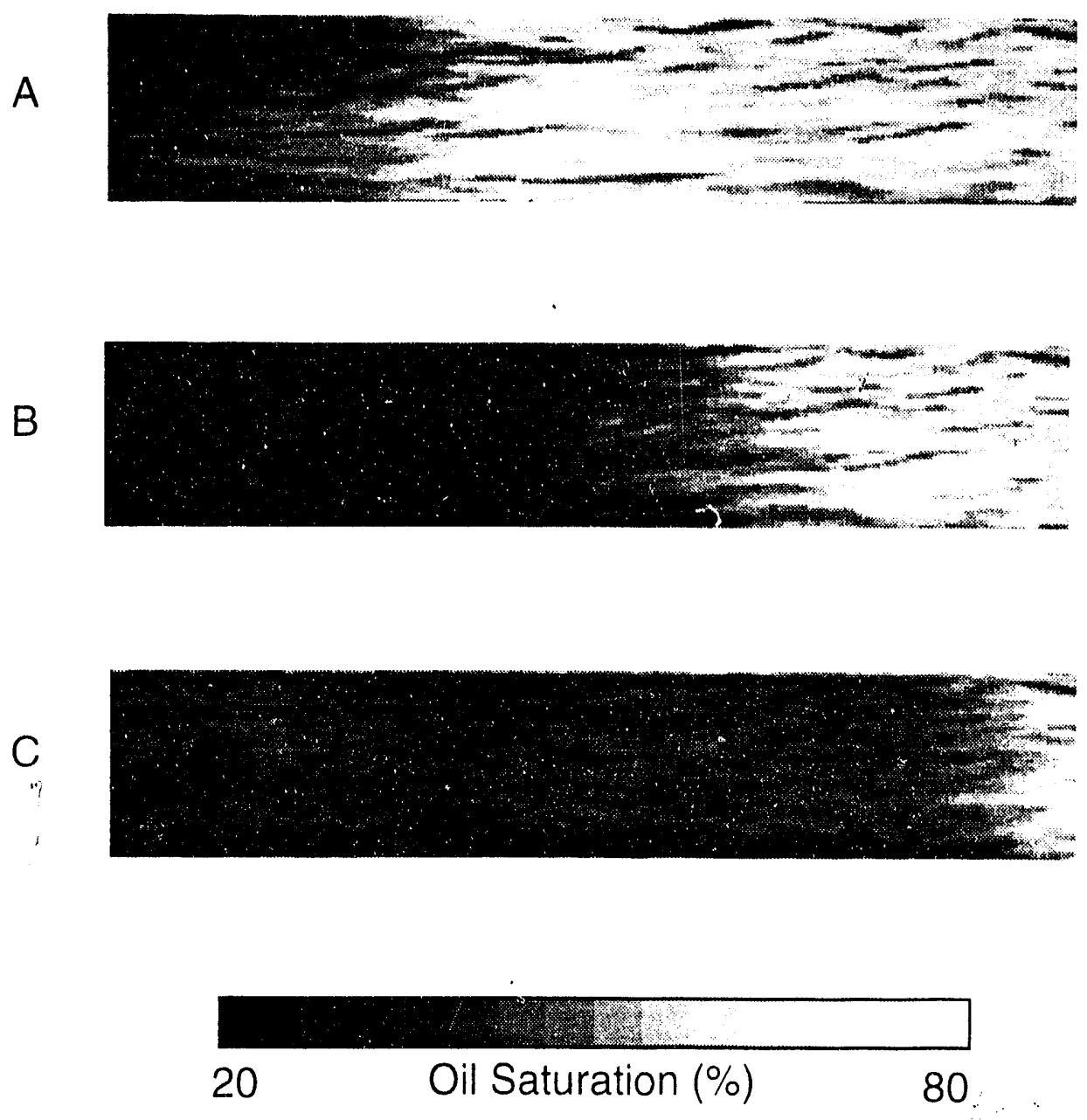

Fig. 25. Waterflood (1CP) of oil saturated (residual brine) Tallant sandstone sample. - C"T measurements: A - 0.14 pore volume; $B-0.23$ pore volume; $C-0.33$ pore volume. 

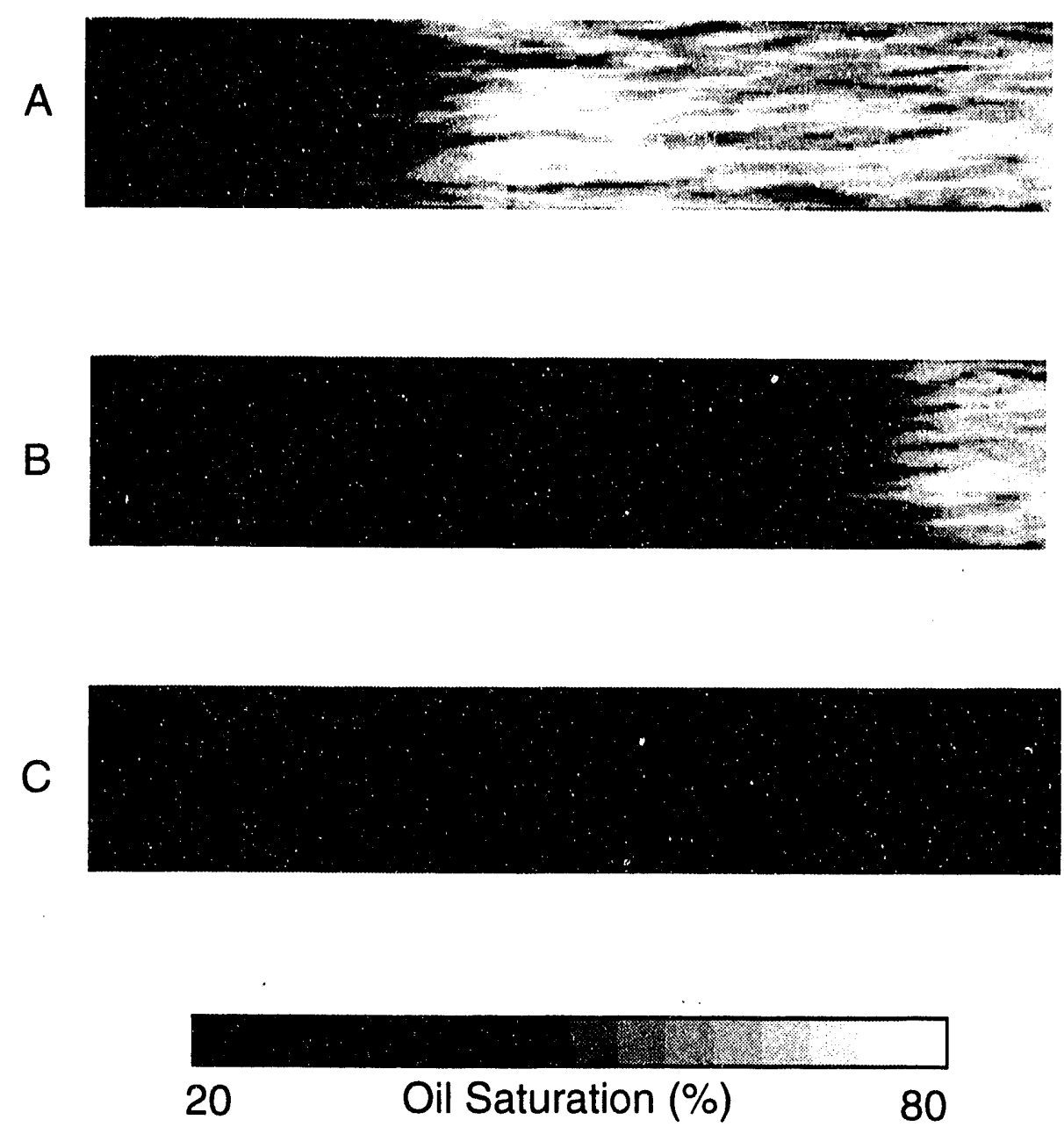

Fig. 26. Waterflood (2.6cP) of oil saturated (residual brine)Tallant sandstone sample. - CT measurements: A - 0.14 pore volume; B - 0.31 pore volume; C - 0.44 pore volume. 

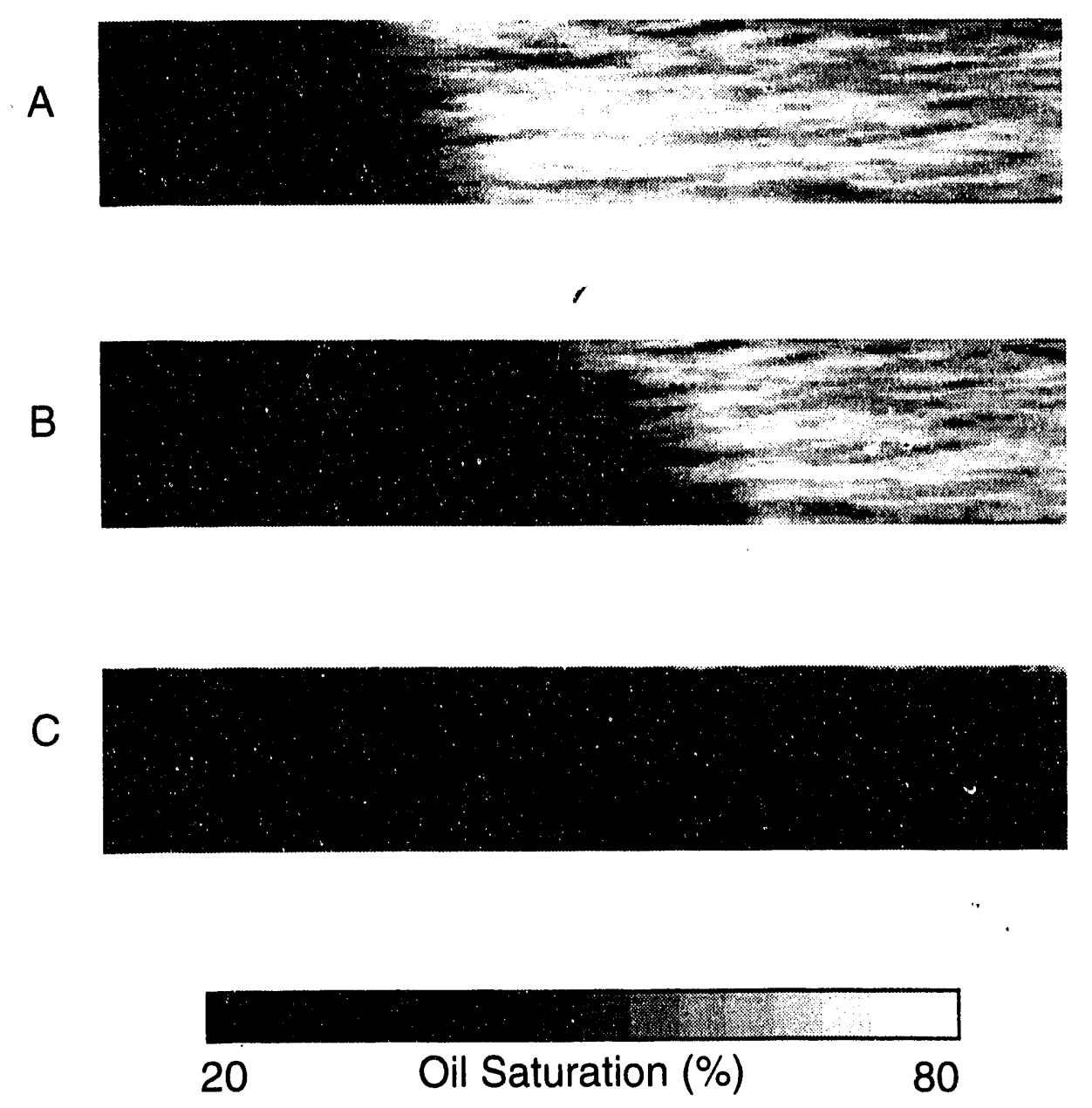

Fig. 27. Waterflood $(23 \mathrm{cP})$ of oil saturated (residual brine) Tallant sandstone sample. - CT measurements: A - 0.14 pore volume; $B-0.24$ pore volume; $C-0.44$ pore volume. 

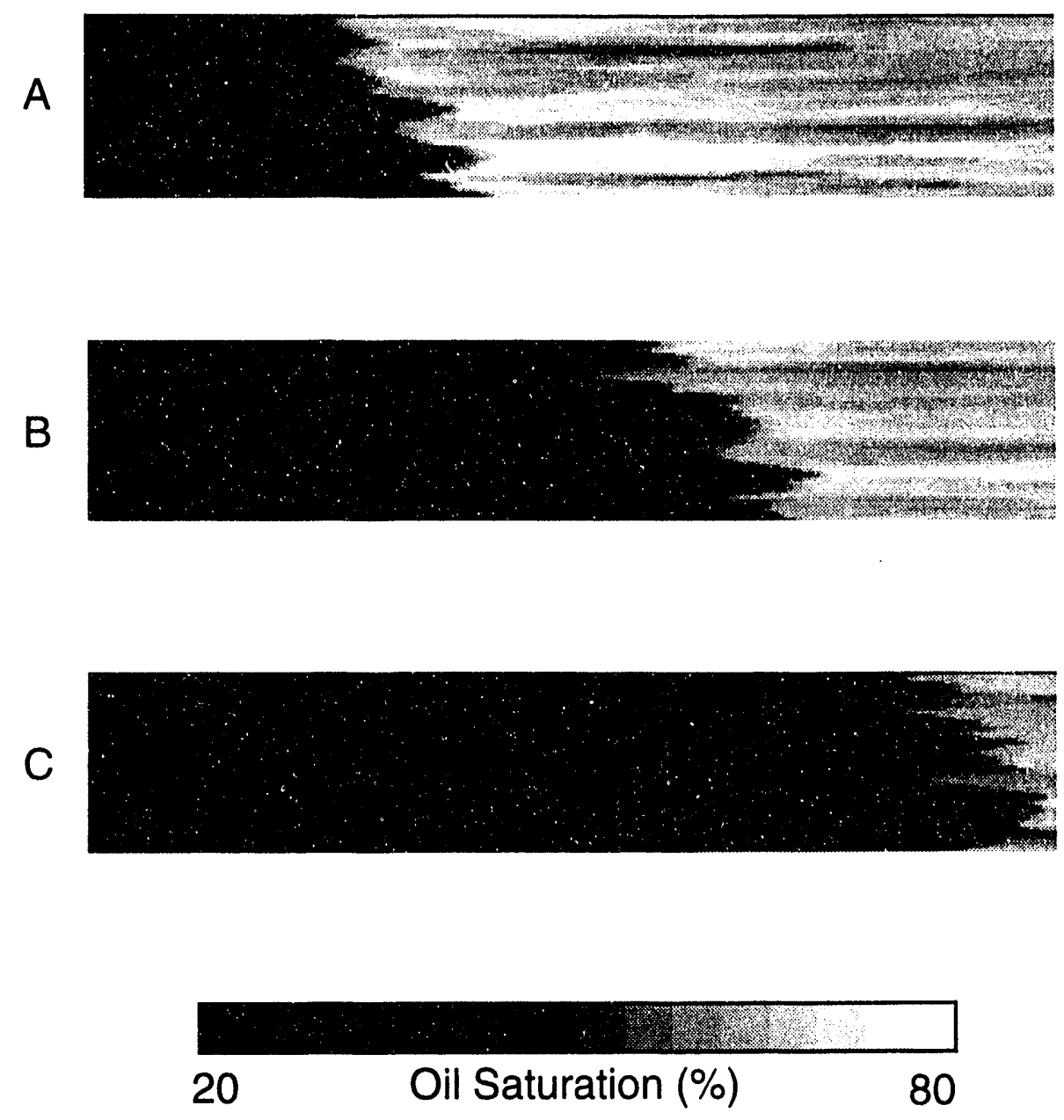

Fig. 28. Waterflood ( $1 \mathrm{cP}$ ) of oil saturated (residual brine)Tallant sandstone sample. - Simulation using $\mathrm{C} \Gamma /$ thin section image analysis data: $\mathrm{A}-0.12$ pore volume; $\mathrm{B}-0.24$ pore volume; $\mathrm{C}-0.33$ pore volume. 

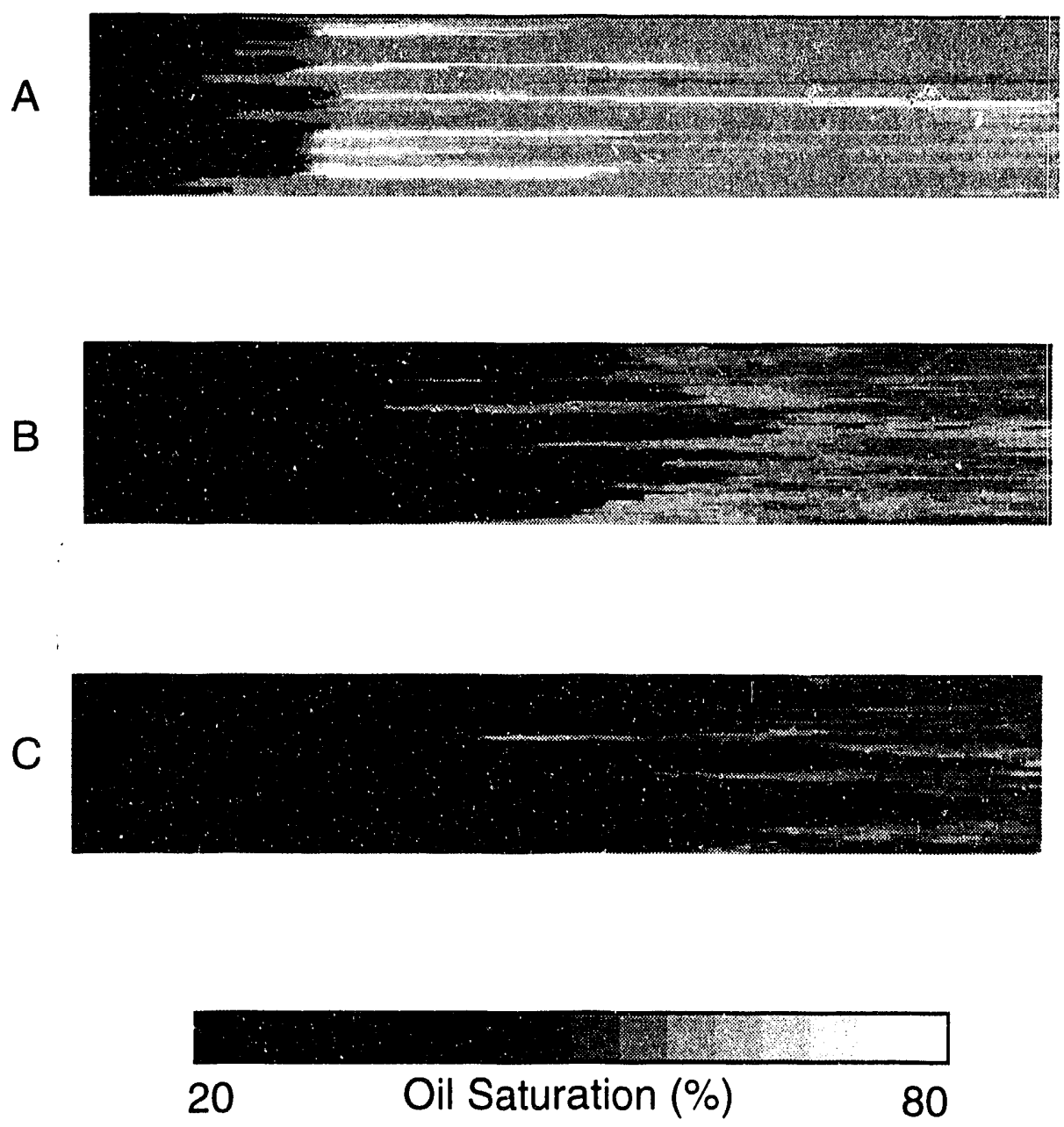

Fig. 29. Waterflood (1cP) of oil saturated (residual brine)Tallant sandstone sample. - Simulation using Turning Bands generated data: A - 0.09 pore volume; B -0.26 pore volume; $\mathrm{C}-0.34$ pore volume. 

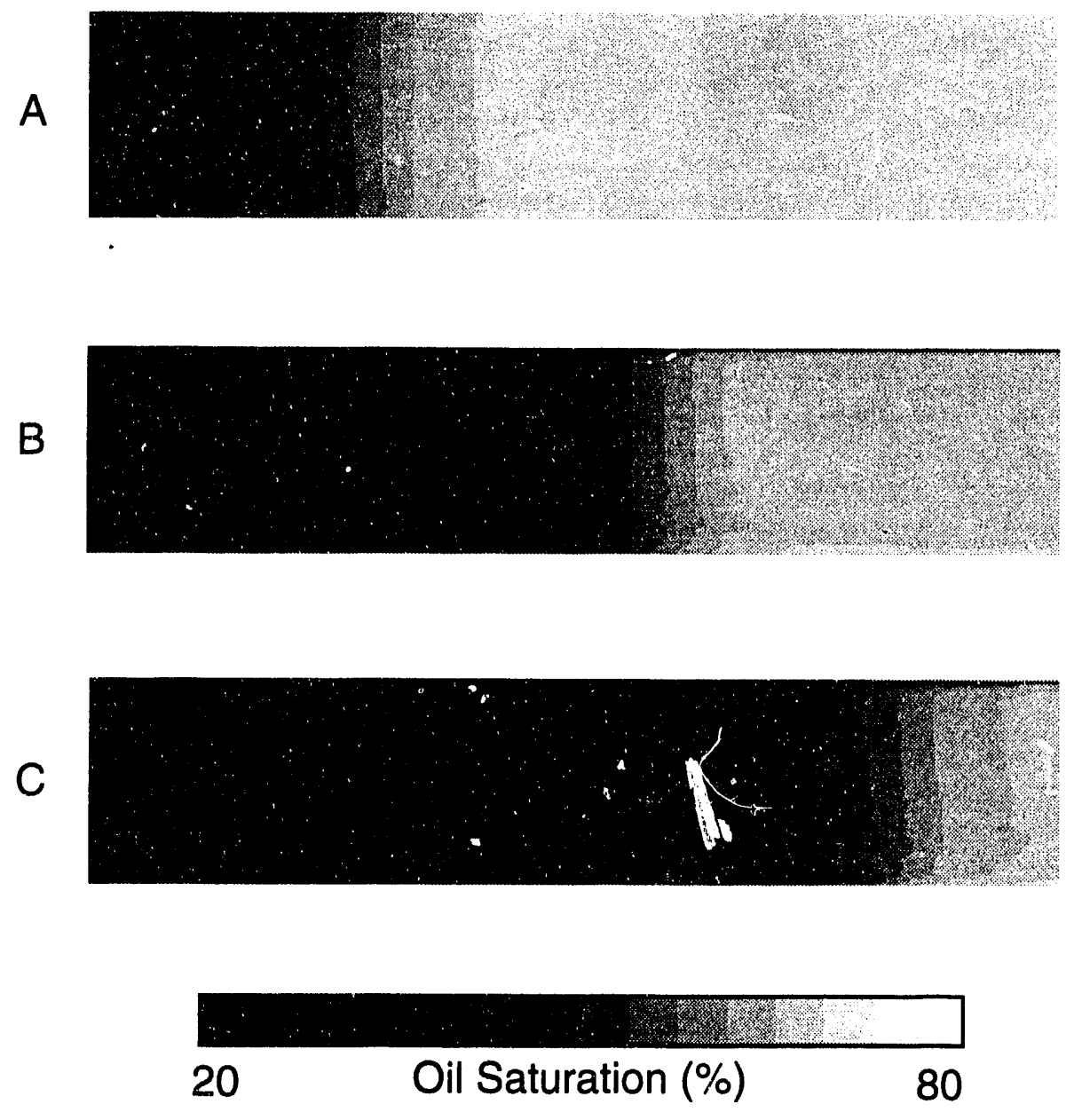

Fig. 30. Waterflood (1cP) of oil saturated (residual brine)uniform permeability sample(simulation): A - 0.09 pore volume; $B-0.26$ pore volume; $C-0.34$ pore volume. 


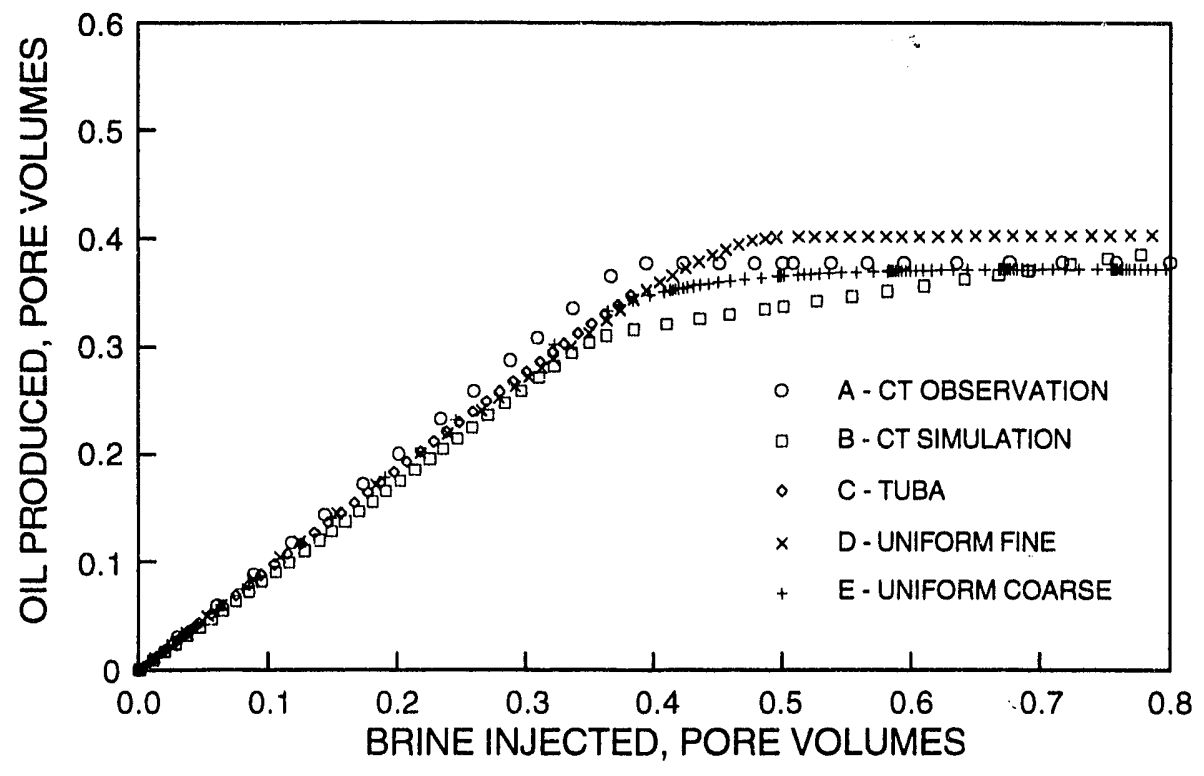

Fig. 31. Oil production curves, $1 \mathrm{cP}$ viscosity: A - CT observation; B - CT simulator; C - Turning Banks simulation; $D$ - Uniform fine grid simulation; $E$ - uniform work grid simulation. 

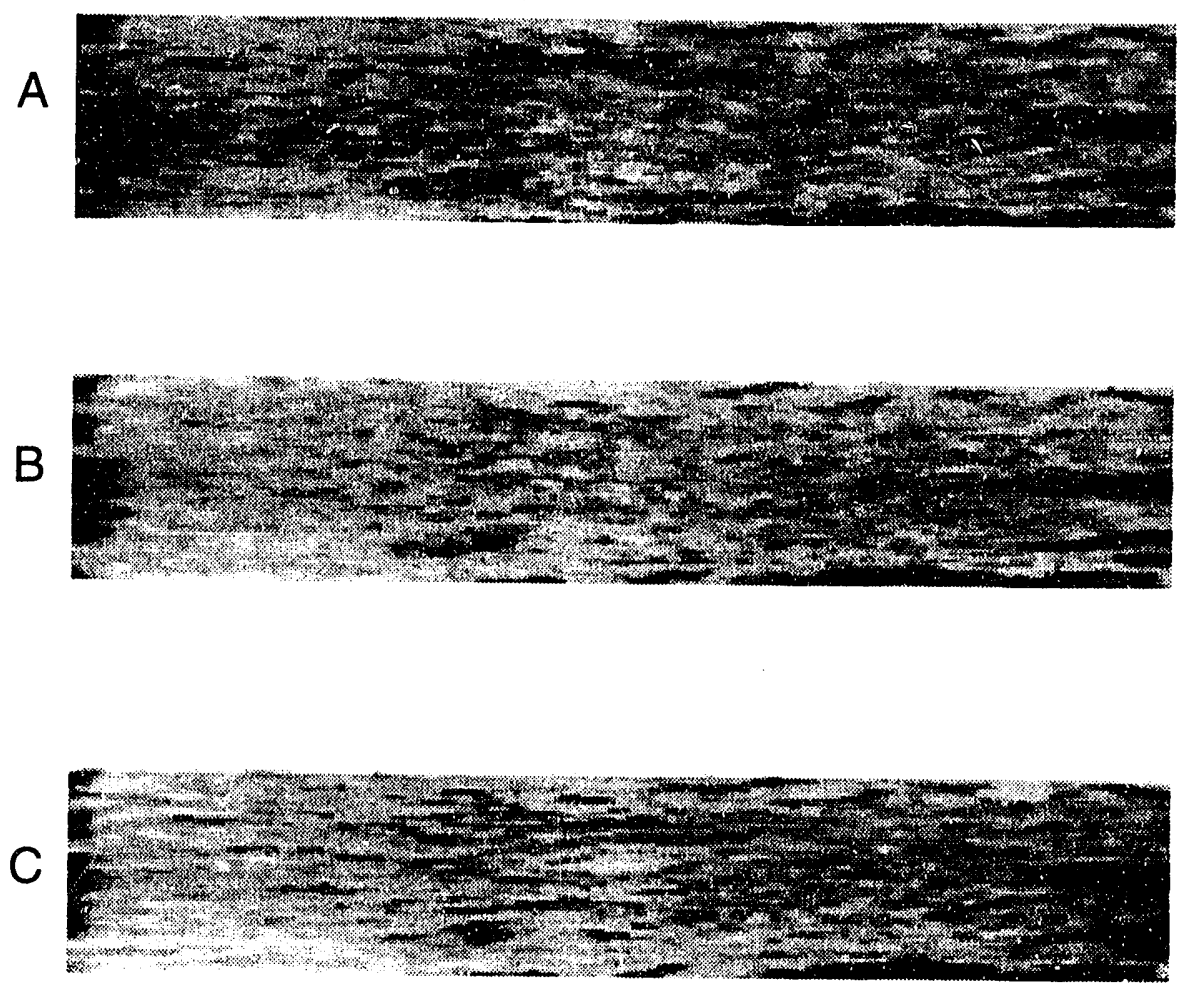

Fig. 32. Oil saturation distributions at residual oil (CT measurements):A - 1 cp oil; B $-2.3 \mathrm{cp}$ oil; C $-26 \mathrm{cp}$ oil. 


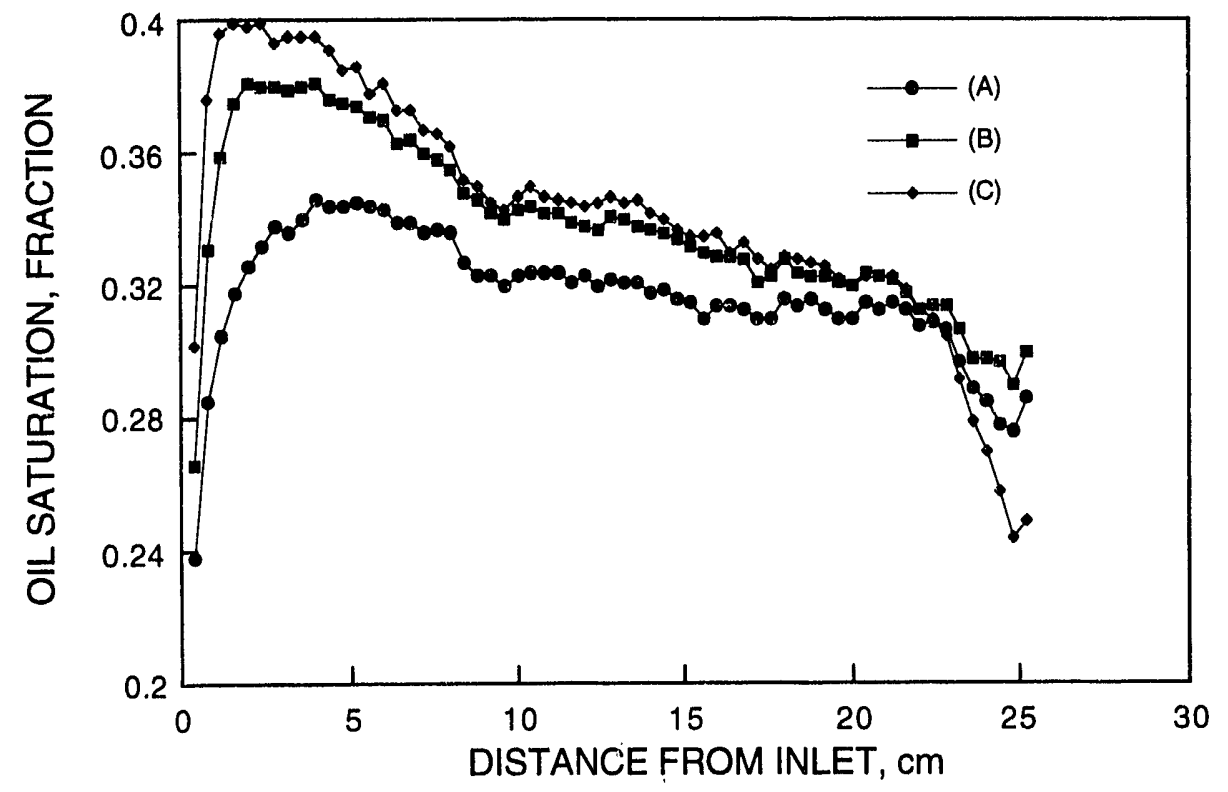

Fig. 33. Average oil saturation longitudinal profile at residual oil (CT measurements): A - 1 cp oil; B - $2.6 \mathrm{cp} \mathrm{oil}$; C - $23 \mathrm{cp}$ oil. 
